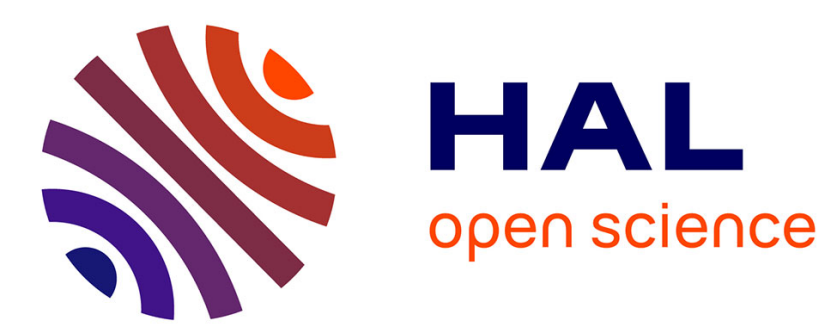

\title{
Impact of air intake position on fire dynamics in mechanically ventilated compartment
}

Lahna Acherar, Hui-Ying Wang, Jean Pierre Garo, Bruno Coudour

\section{To cite this version:}

Lahna Acherar, Hui-Ying Wang, Jean Pierre Garo, Bruno Coudour. Impact of air intake position on fire dynamics in mechanically ventilated compartment. Fire Safety Journal, 2020, 10.1016/j.firesaf.2020.103210 . hal-03019941

\section{HAL Id: hal-03019941 \\ https://hal.science/hal-03019941}

Submitted on 23 Nov 2020

HAL is a multi-disciplinary open access archive for the deposit and dissemination of scientific research documents, whether they are published or not. The documents may come from teaching and research institutions in France or abroad, or from public or private research centers.
L'archive ouverte pluridisciplinaire HAL, est destinée au dépôt et à la diffusion de documents scientifiques de niveau recherche, publiés ou non, émanant des établissements d'enseignement et de recherche français ou étrangers, des laboratoires publics ou privés. 
Impact of air intake position on fire dynamics in mechanically ventilated compartment

Lahna ACHERAR, Hui-Ying WANG, Jean Pierre GARO and Bruno COUDOUR

Institut P', Fluides-Thermique-Combustion, CNRS, ENSMA, Université de Poitiers, BP 40109, 86961 Futuroscope Chasseneuil Cedex, France

wang@ensma.fr

\begin{abstract}
The effects of air intake position on the burning behaviour of liquid pool inside a mechanically ventilated compartment are analysed by using both an experiment and a physics-based model. A series of compartment fire experiments has been undertaken from a reduced scale enclosure with a length/height and width of $2 \mathrm{~m}$. An external ventilation system consists of an air admission duct placed in low or high position inside the compartment, providing an Air Change Per Hour (ACPH) in a range from 1 to 4. Lowering the inlet duct enhances fuel-air mixing in the compartment. The experimental and numerical studies highlight a faster fire growth for a low air intake with a rise of $\mathrm{ACPH}$, implying more dangerous fire with regarding the more important peak in heat release rate and heat feedback to liquid fuel surface. For air intake in high position, the direction of air jet inside enclosure is found to be orthogonal to the direction of the buoyancy-induced flow. This results in an air entrainment restriction towards the fire base and a decrease of the heat feedback to liquid fuel surface due to cooling effect on the hot smoke layer near the ceiling. Thus a high inlet contributes to a reduction by a factor of $40 \%$ in HRR, and the fire growth power is practically independent to ACPH. Moreover, for a high inlet, fire exhaust occurs more easily because both the heat feedback and air entrainment are weaker than these for a low inlet. As a consequence, changing air intake position from low to high leads to a change in fire regime from an under-ventilated fire to an over-ventilated one.
\end{abstract}

\title{
KEYWORDS:
}

enclosure fire, liquid fuel, air intake position, extraction duct, depression, heat feedback

\section{NOMENCLATURE LISTING}

a fire growth factor

$\mathrm{A}_{\mathrm{L}} \quad$ leakage area

C attenuation coefficient

$\mathrm{C}_{\mathrm{p}} \quad$ specific heat

D diameter of fuel pan

D* characteristic length of pool fire

$\mathrm{dx} \quad$ grid size

Fr Froude number

g gravity

$\mathrm{H}_{\text {eav }}$ Heaviside unit step function

L characteristic length of enclosure

$\dot{\mathrm{m}} \mathrm{F} \quad$ mass loss rate of liquid fuel

$\dot{\mathrm{m}}_{\mathrm{A}}$ air flow rate

$\mathrm{P}_{0} \quad$ atmospheric pressure

$\mathrm{P} \quad$ enclosure pressure 
$\overline{\dot{q}}_{s, r} \quad$ mean radiant heat flux over liquid surface

$\dot{q}^{\prime \prime}{ }_{\text {mea }}$ measured radiant heat flux inside liquid pan

$\dot{q}_{s, r} \quad$ derived radiant heat flux over liquid surface

$\dot{Q}_{\text {eff }}$ effective heat release rate

$\dot{\mathrm{Q}}_{\text {the }}$ theoretical heat release rate

$\mathrm{R}$ radius of the pool

$\mathrm{Re} \quad$ Reynolds number

s stoichiometric coefficient

$\mathrm{T}$ temperature

$\mathrm{t}$ time

$\mathrm{t}_{1} \quad$ growth time

u velocity

V volume of combustion zone

$\dot{\mathrm{V}}_{\text {max }}$ maximum volume flow rate

$\dot{\mathrm{V}}_{\text {leak }} \quad$ volume flow rates from leakages

$\mathrm{Y}_{\mathrm{i}} \quad$ mass fraction of hydrocarbon, $\mathrm{O}_{2}, \mathrm{CO}, \mathrm{H}_{2}$

$\mathrm{Y}_{\mathrm{O} 2, \mathrm{lim}}$ critical oxygen concentration for extinction

$z_{f} \quad$ depth of liquid fuel

$z_{w} \quad$ depth of water

$\mathrm{x}, \mathrm{y}, \mathrm{z}$ coordinates system in numerical simulation

Greek

$\rho \quad$ volume density

$\rho_{\infty} \quad$ ambiant volume density

$\tau_{\text {mix }} \quad$ key mixing timescale

$v \quad$ kinetic viscosity

$\tau \quad$ time scale in combustion model

$\phi \quad$ global equivalence ratio

$\lambda$ thermal conductivity

$\eta \quad$ combustion efficiency

$\mu_{f} \quad$ absorption coefficient of liquid fuel

$\mu_{w} \quad$ absorption coefficient of water

$\Delta \mathrm{P}_{\max }$ maximum pressure difference

$\Delta \mathrm{P} \quad$ pressure difference

$\Delta H_{c} \quad$ energy released per kilogram of fuel consumed

\section{Acronym}

ACPH Air Change Per Hour

EDC Eddy Dissipation Concept

GER Global Equivalence Ratio

HRR Heat Release Rate

HVAC Heating Ventilation Air Conditioning

MLR Mass Loss Rate

\section{INTRODUCTION}

Fire safety in confined spaces, e.g. nuclear installation equipped with forced or mechanical ventilation [1-6] or increasingly popular low-energy consumption type of buildings [7, 8], is a 
concern that should be dealt with carefully. Under-ventilated fire in confined spaces shows higher carbon monoxide and soot yields because of inadequate air intake to sustain combustion $[9,10]$. A reversion of the flow pattern inside enclosure causes an increase of unburnt fuel concentration [11]. Hot smoke generated from the enclosure fire or even flame would spread out from the extraction duct [12]. Some enclosure fire experiments [13, 14, 15] were conducted to display the phenomena of periodic oscillations and temporary flame quenching in a highly confined compartment due to a decrease in oxygen concentration. It was experimentally observed $[13,14]$ that the successive combustion of a non-negligible quantity of unburnt fuel gases inside a vitiated air enclosure due to an increasing pyrolysis rate contributes to the lowfrequency oscillating flame which moves away from the pool towards the air inlet.

Overflows and leakage from oil product containers during storage may cause large damage and trigger further accidents in case of ignition. Based on the measured radiative heat flux or flame temperature, empirical models have been established $[16,17]$ to evaluate the MLR of liquid fuel in large enclosures where the heat fluxes from hot wall can be negligible. The liquid fire growth rate in confined spaces is more important than the one in open atmosphere [18] due to an additional contribution of the radiation heat flux from the hot smoke and walls of an enclosure to the degradation of condensed fuel into pyrolysis gases. The agreement between experimental data and fully predictive simulation is fair concerning the burning rate of liquid fuel in an enclosure [19]. It demonstrated that only using the MLR collected experimentally, CFD modelling is capable of predicting the thermal behaviour [20], visibility [21] and pressure [22] with satisfactory accuracy. More work on confined fire in several high-consequence fields, such as the nuclear safety area, have been done for verification and validation of selected fire models [23].

Air intake position is located either in the upper or lower part of a compartment [1-8]. When air inlet is in low position in close proximity to fire source, they interact and ultimately behave like a fire under windy conditions, resulting in a higher MLR [2, 19]. It is found that the fire growth rate remains moderate for a high air inlet with appearance of the fire oscillations as a result of a restriction in air entrainment [19]. Effects of air intake position on the behavior of a fire compartment scenarios have been investigated [3-6], notably on the stratification of product gases concentration and temperature in a full scale compartment with mechanically-ventilated pool fire. These studies [3-6] have shown that the compartment behaves as a well-stirred reactor when the ventilation inlet is in high position. In terms of oxygen concentration distribution, forced ventilation results in a well-mixed compartment regardless of ACPH for a high inlet [1]. Whereas, the well-stirred reactor approach is not applicable for a low inlet because oxygen concentration in the compartment tends to be stratified. Through analysis of heat feedback and oxygen concentration, this investigation tends to identify the main reasons leading to a diminution of HRR with an increase of ACPH for a high inlet and on the contrary, an enhancement of HRR for a low inlet. In order to improve the credibility of performing safe and successful prescribed confined fire, the numerical simulation is also performed by using FDS6.7 [24]. In comparison with the experimental data, it is found that an accuracy of prediction on the enclosure fire development depends on the studied fire scenario even by using the measured burning rate curves as an input.

\section{EXPERIMENTAL SET-UP}

Since fire experiments in full scale are expensive, the numbers of tests are limited. The current compartment fire tests have been conducted at a reduced geometric scale thanks to the PERICLES platform of the PPRIME Institute in France. A schematic of the 3D view of the 
experimental facility is illustrated in Fig.1(a, b). The enclosure is $2 \mathrm{~m}$ in length/height/width, and equipped with an external ventilation system. The air intake was placed either in low position at a height of $0.3 \mathrm{~m}$ (cf. Fig.1a) or in high position at a height of $1.7 \mathrm{~m}$ (cf. Fig.1b). The burnt gases were directed to the extraction duct with a length of $1.1 \mathrm{~m}$ at a height of $1.7 \mathrm{~m}$. The dilution duct with a length of $2.5 \mathrm{~m}$ is fixed at the same height. All ventilation ducts have a square section of $0.2 \times 0.2 \mathrm{~m}^{2}$, and are made of smooth galvanized steel. The bottom boundary of the rock wool is taken to be perfectly insulated. Walls of the enclosure are made of $20-\mathrm{cm}-$ thick cellular concrete with a thermal conductivity of $\lambda=1 \mathrm{~W} / \mathrm{m} / \mathrm{K}$, a density of $\rho=400 \mathrm{~kg} / \mathrm{m}^{3}$, and a specific heat of $\mathrm{C}_{\mathrm{p}}=0.88 \mathrm{~kJ} / \mathrm{kg} / \mathrm{K}$. The performed measurements include MLR, velocity, pressure, temperature, heat flux and chemical species concentrations of gases filling the enclosure. Data acquisition was started from about 2 min before the ignition.

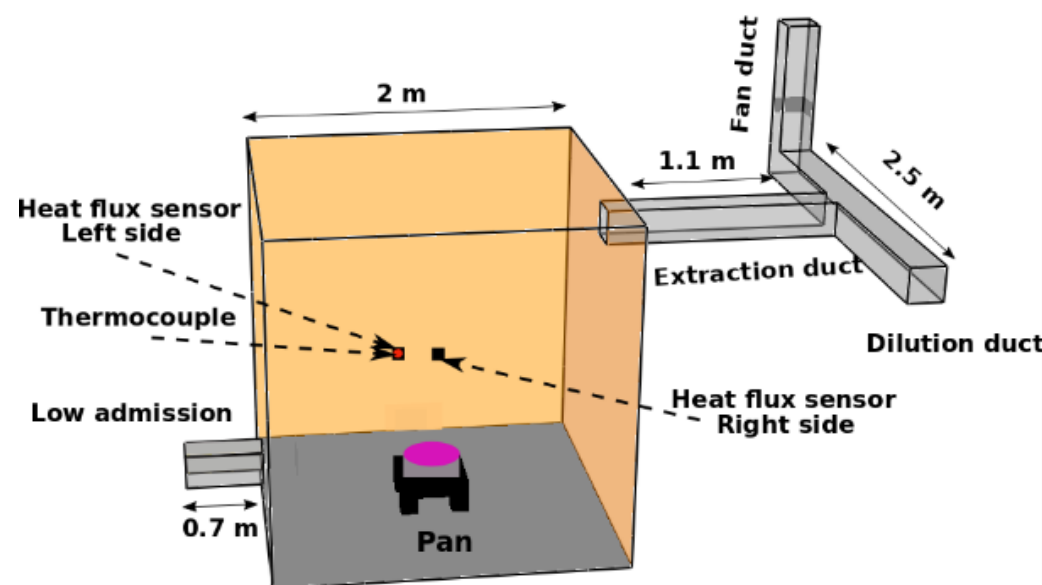

- Thermocouple on the wall $H=48.5 \mathrm{~cm}$, Left side

- Heat flux sensor, $\mathrm{H}=\mathbf{4 8 . 5} \mathrm{cm}$

a) 3D view with air intake in low position

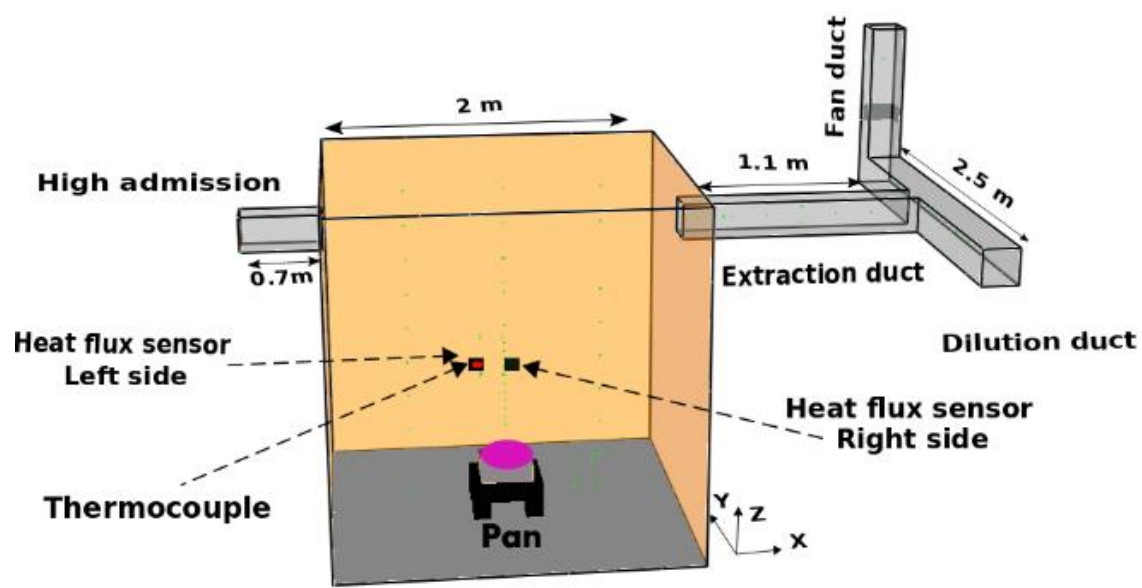

- Thermocouple on the wall $H=48.5 \mathrm{~cm}$, left side

- Heat flux sensor, $\mathrm{H}=48.5 \mathrm{~cm}$

b) 3D view with air intake in high position 


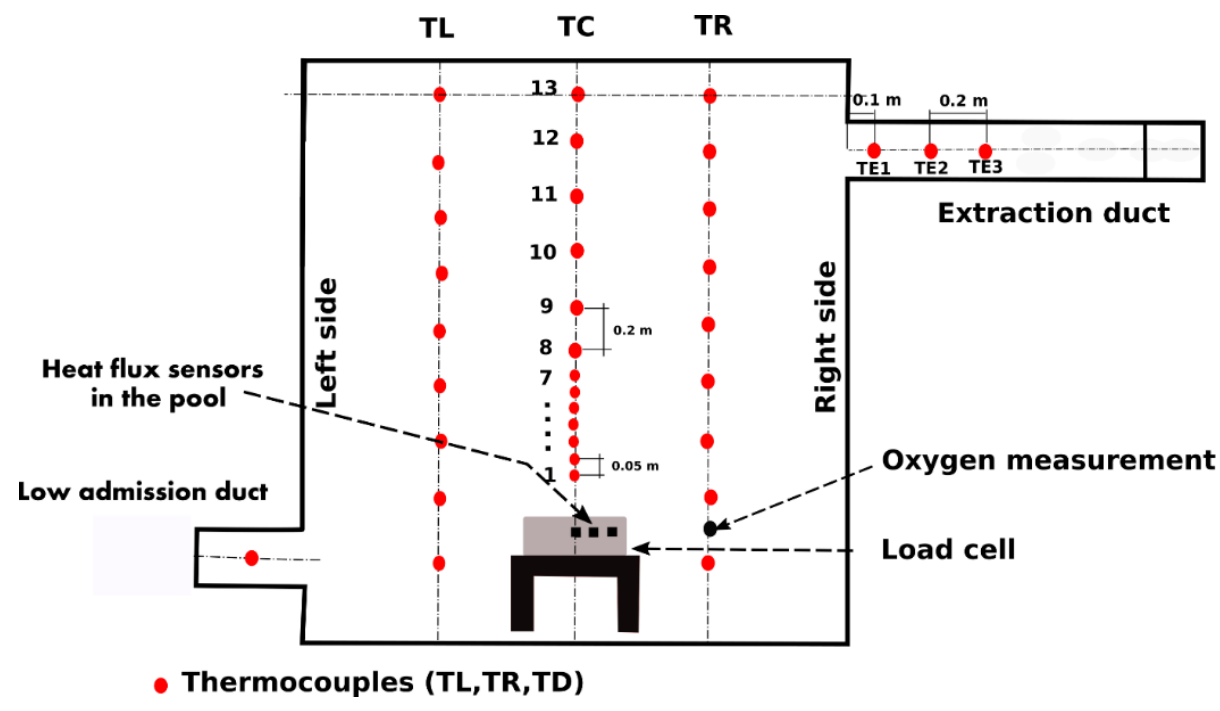

c) side $(\mathrm{x}, \mathrm{z})$ view for the measurement locations with low or high inlet position

Figure 1. Mechanically ventilated enclosure fire connected to an extraction duct

The air flow rates at the intake and dilution ducts are regulated as a function of the depression level by means of an adjustment of rectangular flaps located upstream of these ducts; this allows to generate an aeraulic resistances. The flow rate of gases in the inlet and dilution ducts is measured with hot wire system placed at the entrance of these ducts with a sensitivity below 1\%. A mechanical extraction is carried out by using System-Air Euro S7440, providing a maximum volume flow rate of $\dot{\mathrm{V}}_{\max }=720 \mathrm{~m}^{3} / \mathrm{h}$, and pressure difference of $\Delta \mathrm{P}_{\max }=186 \mathrm{~Pa}$. As shown in Fig.1 $(a, b)$, to select the desired airflow rate, a centrifugal fan with single-phase variable speed is placed at the outlet of a duct which is orthogonal to the dilution duct at a height of $2.6 \mathrm{~m}$. The fan characteristic curve (cf. Fig.2, i.e., delivered flow rate as a function of pressure) is used as an input in the HVAC module [24]. Before activating the fire, a period of 10 minutes was included to establish a depression level which is measured continuously by a pressure captor with a sensitivity of $\pm 2 \mathrm{~Pa}$.

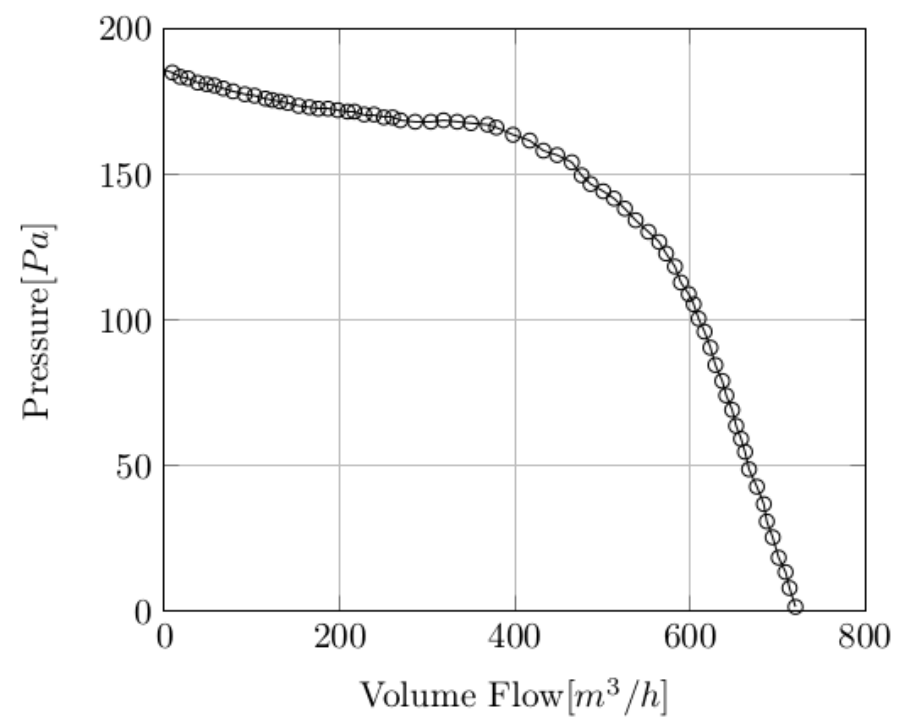

Figure 2. Relationship between pressure and free volume flow rate of the fan. 
In this study, the Reynolds number, which is calculated from the measured inlet velocity at air intake duct, varies from 2000 to 5000 for 1 and 4 ACPH, respectively. It is large enough to ensure a turbulent flow inside the enclosure. The Froude number, $\mathrm{Fr}=\mathrm{u}^{2} / \mathrm{gL}$, is made constant by $\mathrm{u} \propto \mathrm{L}^{1 / 2}$ which is derived from dimensionless variable of momentum conservation [25]. Flow time scale is obtained from mass conservation by $\tau \propto \frac{\mathrm{L}}{\mathrm{u}} \propto \mathrm{L}^{1 / 2}$. Since the ventilation flow rate is the inverse of $\tau$, it scales with $\mathrm{L}^{-1 / 2}$. Based on the dimensionless variable of energy equation, the source term contains a Zukoski number [25], defined as :

$$
\mathrm{Zu}=\frac{\dot{\mathrm{Q}}}{\operatorname{Fr}^{5 / 2}\left(\rho \mathrm{C}_{\mathrm{p}} \mathrm{T}\right) \mathrm{g}^{1 / 2}}
$$

By adapting the above several scaling laws and preserving the ratio, $\dot{Q}^{2} / L^{5}$, a good similitude in the physical phenomenon can be obtained between the reduced scale experimental device with a volume of $8 \mathrm{~m}^{3}$ and a full scale $100 \mathrm{~m}^{3}$ compartment with a HRR below $1 \mathrm{MW}$.

Fig.1c shows the measurement locations with low or high inlet position. The temperature measurements in the compartment were performed with chromel-alumel thermocouples (type $\mathrm{K}$ ) of a $0.5 \mathrm{~mm}$ wire with three vertical arrays, at the extraction and dilution ducts. The first array of 13 thermocouples was positioned in the center of the compartment starting from a height of $0.55 \mathrm{~m}$ above the ground at regular intervals of $0.05 \mathrm{~m}$ and $0.2 \mathrm{~m}$. The second and third array of 10 thermocouples were located at $0.45 \mathrm{~m}$ from the left and right walls, respectively. The first thermocouple was placed at a height of $0.1 \mathrm{~m}$ above the ground and the others were located at regular intervals of $0.2 \mathrm{~m}$. Temperature on the behind wall was also measured using a $\mathrm{K}$ type thermocouple which was located at $0.075 \mathrm{~m}$ from the central axis of the wall at a height of $0.48 \mathrm{~m}$. The uncertainty in the measurement of gas temperature by using thermocouples is estimated within $5-10 \%$ by taking into account a multitude of potential errors, including thermal mass inertia, accumulation of soot particles, surface reactions and radiation.

Local continuous measurement of molar fraction of oxygen outside the fire at $0.3 \mathrm{~m}$ from the pool edge of the flame base was performed. The COSMA No-Dispersive Infrared (NDIR) gas analyzer was used to follow the evolution of $\mathrm{CO}$ and $\mathrm{CO}_{2}$ concentrations, and the paramagnetic gas analyzer was used to follow the evolution of $\mathrm{O}_{2}$ concentration. Moreover, these measurements were verified by using another gas analyzer as Testo_350 [12]. In order to avoid condensation of the sampled gases, the COSMA gas analyzer consists of a pump, allowing the sampled gases to be transported to analysis cabinet through a heated line $\left(115^{\circ} \mathrm{C}\right)$. A sample is analyzed with a time lag which can be estimated between 60 and $80 \mathrm{~s}$ depending on the test. This generates a gap between HRR and oxygen concentration. By using the same method, the previous works $[1,2]$ showed that the forced ventilation results in a well-mixed compartment regardless of $\mathrm{ACPH}$, and the level of oxygen concentration is practically identical far away from the fuel pan. Of course, close to the fuel pan, strong variations of oxygen concentration exist.

Radiant heat flux below $20 \mathrm{~kW} / \mathrm{m}^{2}$ over the fuel surface was measured by means of three Gardon-gauge-type radiometers MEDTHERM for three radial positions of $0,1 / 3 \mathrm{R}$ and 2/3R. The detailed measurement method can be found in Refs. [26, 27]. Each radiometer was water cooled and equipped with a window to eliminate the conductive and convective components from the flame. The window used was in calcium fluoride with a spectral transmittance between 0.3 and $11.5 \mu \mathrm{m}$ which covers the spectral range of a luminous flame between 0.5 and $5 \mu \mathrm{m}$. 
The view factor of these radiometers was $150^{\circ}$ and uncertainty in heat flux measurements is within 3\%. Position of the flux meters inside liquid is shown in Figure 3. The radiometers were horizontally oriented and submerged in water. In addition, the measured values were corrected by taking into account the influence of the pan rim which partially masks the view fields of the radiometers. Before each test, water was first added to protect the heat flux gauges positioned in the bottom of the fuel pan. This was followed by the fuel until it reached $1 \mathrm{~mm}$ below the pan lip. The underlying water allows to avoid a gradual heating of the tank which would cause an acceleration of heptane degradation with a HRR peak at the end of the fire due to the heptane boiling. To avoid the conductive heat transfer from the stainless steel pans, the ratio of the fuel height to the pool diameter is maintained to about $12 \%$ by adjusting the water layer height. Heptane pool combustion was initiated at ambient temperature using a propane gas burner. The boiling point of heptane $\left(98^{\circ} \mathrm{C}\right)$ is below that of water, allowing to avoid any serious splashing effect of water droplets due to boil over, which disturbs the measurements.

Knowing the accurate initial fuel level position, the location of the radiometer and the instantaneous burning rate, it is possible to deduce the evolution of the radiant heat flux received by the fuel as a function of the distance from the sensitive surface of the radiometer. Based on this method [26, 27], the measured radiant heat flux inside the liquid pan $\dot{q}^{\prime \prime}{ }_{\text {mea }}$ is divided by an attenuation coefficient $\mathrm{C}$ as a function of time, as follows :

$\dot{q}^{\prime \prime}{ }_{s, r}(r)=\dot{q}^{\prime \prime}{ }_{m e a}(r) / C$ with $C=\left(e^{-\mu_{f} z_{f}} \cdot e^{-\mu_{w} z_{w}}\right)$

This treatment allows to take into account the radiation loss by absorption inside the pan through water and fuel (heptane) layers above the radiometers. The mean radiant heat flux at the surface is determined by integrating radiation heat flux, $\dot{q}_{s, r}$, along the pan radius, as follows :

$\overline{\dot{q}}_{s, r}=\frac{8}{D^{2}} \int_{0}^{\frac{D}{2}} \dot{q}^{\prime \prime}{ }_{s, r}(r) d r$

It should be noted that the location of the radiometers was performed with a location accuracy of $+/-0.25 \mathrm{~mm}$. Thus the deduced radiant heat fluxes at the fuel surface were only a rough approximation with an uncertainty up to $20 \%$ [26, 27], mainly due to the measured layer depth, Z.

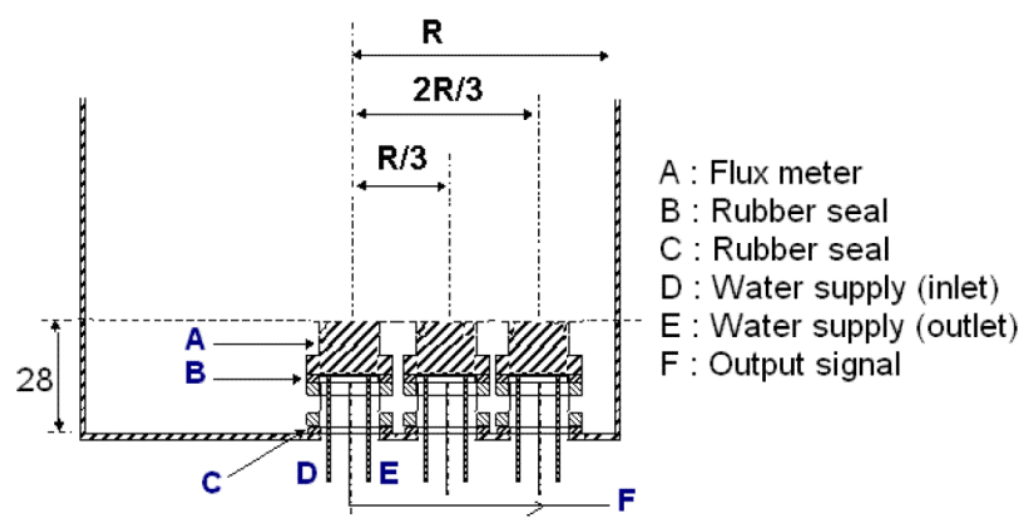

Figure 3. Position of the flux meters inside liquid

The liquid fuel pan with a diameter varying from 23,26 to $30 \mathrm{~cm}$ was placed in the middle of the enclosure, slightly elevated at a height of $0.3 \mathrm{~m}$. The mass loss rate of liquid fuel was measured by a SCAIME load cell [27] which was positioned under the pan. The load cell has a response time of $60 \mathrm{~ms}$ with an uncertainty of measurements within $5 \%$. For each fuel pan, ACPH varies from 1 to 4 , corresponding to a volume flow rate of 24 and $40 \mathrm{~m}^{3} / \mathrm{h}$, respectively. 
For each fire condition, three tests were made in order to check the repeatability of the main parameters, and a total of 72 tests were performed. A good repeatability was obtained with a difference below $2 \%$ regarding the mass loss rate, pressures and species concentrations for heptane pan below $26 \mathrm{~cm}$ in diameter. With a heptane pan of $30 \mathrm{~cm}$, the oscillating flame close to extinction in under-ventilated conditions becomes very perturbed. Repeatability of the worst case for a high inlet position during three fire tests is presented in Fig.4(a-c). The average difference in mass loss rate between the three tests is in an order of $0.2 \mathrm{~g} / \mathrm{s}$, except close to the extinction point. The relative deviation of the species concentration does not exceed $2 \%$ and the difference in depression level is about $\pm 3 \mathrm{~Pa}$.

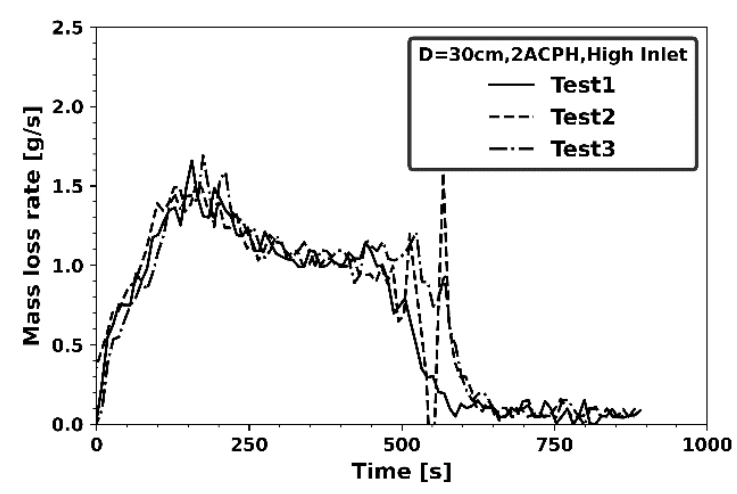

a) Mass loss rate

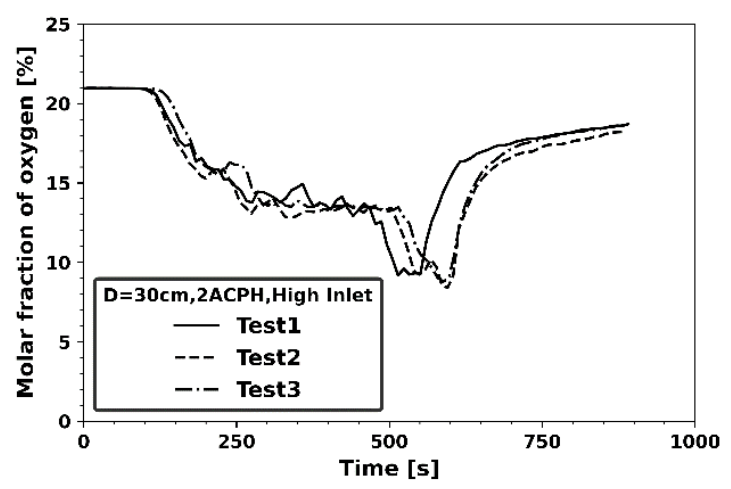

b) Oxygen concentration

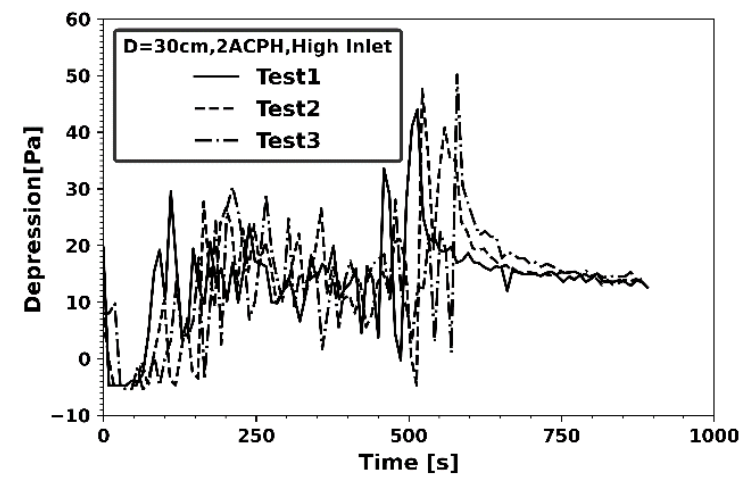

c) Pressure inside enclosure

Figure 4. Repeatability of three fire tests for a fuel pan of $30 \mathrm{~cm}$ with a high inlet position

\section{NUMERICAL MODELLING}

The 3D computational domain for the numerical simulation is shown in Fig.1(a, b). The computational model of the pool is square with an equivalent fuel pan in diameter. A physicsbased continuum model is used, wherein governing equations for the various thermo-physical phenomena involved in fire are solved numerically. A detailed description of the threedimensional physics-based model can be found in FDS6 user guide [24] and references therein. This section provides only a summary of the physics-based model utilized in the current work.

The turbulent combustion processes are assumed to be governed by the conservation equations for the mass fraction of the seven major chemical species, such as $\mathrm{C}_{\mathrm{n}} \mathrm{H}_{2 \mathrm{n}+2}, \mathrm{O}_{2}, \mathrm{CO}, \mathrm{H}_{2}, \mathrm{CO}_{2}$, $\mathrm{H}_{2} \mathrm{O}$ and $\mathrm{N}_{2}$ via the four sequential, semi-global steps [28]. 

i) $\mathrm{C}_{\mathrm{n}} \mathrm{H}_{2 \mathrm{n}+2} \rightarrow \frac{\mathrm{n}}{2} \mathrm{C}_{2} \mathrm{H}_{4}+\mathrm{H}_{2}$
ii) $\mathrm{C}_{2} \mathrm{H}_{4}+\mathrm{O}_{2} \rightarrow 2 \mathrm{CO}+2 \mathrm{H}_{2}$
iii) $\mathrm{CO}+\frac{1}{2} \mathrm{O}_{2} \rightarrow \mathrm{CO}_{2}$
iv) $\mathrm{H}_{2}+\frac{1}{2} \mathrm{O}_{2} \rightarrow \mathrm{H}_{2} \mathrm{O}$

The local HRR is calculated from an Eddy Dissipation Concept (EDC) [24], as follows :

$$
\dot{\mathrm{Q}}_{\mathrm{eff}}=-\sum_{\mathrm{i}} \mathrm{V} \cdot \frac{\rho}{\tau_{\text {mix }}} \min \left(\mathrm{Y}_{\mathrm{i}}, \frac{\mathrm{Y}_{\mathrm{O} 2}}{\mathrm{~s}}\right) \cdot \mathrm{H}_{\mathrm{eav}}\left(\mathrm{Y}_{\mathrm{O} 2}-\mathrm{Y}_{\mathrm{O} 2, \mathrm{lim}}\right) \cdot \Delta \mathrm{H}_{\mathrm{c}, \mathrm{i}}
$$

Here, $\mathrm{i}$ denotes the primary fuel, $\mathrm{CO}$ and $\mathrm{H}_{2}$. The key mixing timescale, $\tau_{\text {mix }}$, is supposed to relate approximately to the three processes such as diffusion, subgrid-scale advection, and buoyant acceleration. The source term is multiplied by $\mathrm{H}_{\text {eav }}\left(\mathrm{Y}_{\mathrm{O} 2}-\mathrm{Y}_{\mathrm{O} 2, \mathrm{lim}}\right)$ which is zero when its argument is negative $\left(\mathrm{Y}_{\mathrm{O} 2}<\mathrm{Y}_{\mathrm{O} 2, \mathrm{lim}}\right)$ and 1 when it is positive $\left(\mathrm{Y}_{\mathrm{O} 2}>\mathrm{Y}_{\mathrm{O} 2, \mathrm{lim}}\right)$. Flame extinction occurs when the local oxygen concentration is below a critical value, $\mathrm{Y}_{\mathrm{O} \text {, lim }}$ which is evaluated as a function of specific heat, temperature and chemical composition [24]. Since we lack the ability to measure the enclosure fire power using gas analysis, the predicted HRR from the oxygen limited combustion model (Eq.5) is considered as the effective one.

In vitiated air environment, an incomplete reaction induces soot production. In FDS6 [24], a simple soot conversion model is based on the fraction of fuel mass that is converted into soot within a thin zone corresponding to flame thickness by using a fast EDC combustion model. Such soot yield approach does not incorporate the essential physical processes of soot inception, coagulation, surface growth and oxidation in addition to the influences of turbulent fluctuations and temperature [29]. A soot yield value can be experimentally determined only in wellventilated conditions, e.g., 0.037 for heptane [30] which is used in this numerical work. In fact, the soot yield varies as a function of the degree of air vitiation inside an enclosure fire [10] or Global Equivalence Ratio (GER) [31]. In the current simulation of enclosure fire, the predicted heat flux, gas temperature and species concentration can't be improved in comparison with the experimental data by changing solely the soot yield value in a range of 0.037 to 0.05 . It has long been demonstrated [19] that predicting MLR of liquid fuel via a reliable radiation flux by using a soot yield approach is again impossible in a vitiated air enclosure. The measured MLR curves are usually used as an input in FDS [19]. Soot formation has to be properly calculated through a physical model in order to obtain a reliable radiation heat feedback to the pyrolysis surface of liquid fuel. For heptane fire, soot is usually the most important combustion product controlling the thermal radiation from the flame and hot smoke. The gas behaves as a grey medium, hence an absorption coefficient without spectral dependence is employed in a radiative transfer equation which is solved by using a discrete finite volume method [24].

A dedicated module for modelling Heating, Ventilation and Air-Conditioning (HVAC) systems, consisting of mass, energy and momentum equations, is coupled with the gas phase solver [32]. Fans are included in the HVAC network, and its resulting volume flow rate can be characterized from a basic quadratic formulation [24].

In non-fire condition, a difference in the volume flow rates between the inlet and extraction ducts is experimentally detected with an average value of $\dot{\mathrm{V}}_{\text {leak }} \approx 0.02 \mathrm{~m}^{3} / \mathrm{s}$. That means that the enclosure envelope is not perfectly air tight, providing small paths from the gaps around door and enclosure construction as well as from passage of the thermocouples. The relation between leakage volume flow rate and area as a function of the pressure difference can be described as follows : 


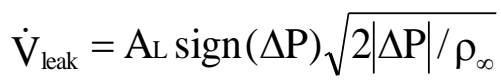

Based on Eq.6, the total leakage area, $A_{L}$, is estimated in the order of $45 \mathrm{~cm}^{2}$ with a depression level, $\Delta \mathrm{P}$, of about $10 \mathrm{~Pa}$ in non-fire condition. From the viewpoint of fire $\mathrm{CFD}$, since leakage is a sub grid-scale phenomenon, a leak path boundary condition can't be directly specified. In FDS simulations [24], the leaks are modelled through the HVAC module as a finite area, $A_{L}$, using vents on the domain boundaries via the leakage flow velocity, $u_{\text {leak }}=\dot{V}_{\text {leak }} / A_{L}(\mathrm{~m} / \mathrm{s})$. The influence of the leakages for this set-up has been examined by using FDS [24]. According to the numerical simulation, after activating the fire, oscillation of the pressure difference (cf. Fig.18) between the inside and outside induces a leakage flow velocity above $4 \mathrm{~m} / \mathrm{s}$ by using this small leakage area. Such a strong air jet significantly disturbs the pool fire if the leakage area is located in low position, or the smoke layer near the ceiling if it is in high position. However, the experimental results show no disturbance of fire or smoke layer by leakage flow. Since we lack the ability to identify the leakage locations (door, passage of the thermocouples, etc.), the bulk leakage method was used over all wall surfaces [7]. With this approach, leakage refers to the amount of air flowing through the enclosure envelope, and does not directly participate in the ventilation of the fuel pans.

In the current simulation, fire boundary conditions are specified as a function of time by using the experimental burning rate curves as an input. A one-dimensional heat transfer equation for the liquid temperature is solved using a finite difference method [24]. The cell size at the liquid interior is selected automatically according to its thermo-physical properties, and is smaller than $\sqrt{\lambda / \rho C_{p}}$ for assuring a good accuracy. By default, the liquid mesh cells increase towards the middle of the material layer and are smallest on the layer boundaries. The cells number is adapted automatically to the thickness of the liquid layer [24] with a depth of $10 \mathrm{~cm}$-height in this study. Liquid fuel as heptane is used, and the detailed information about its thermo-physical and combustion properties [28] is provided in Table 1.

Table 1. Thermo-physical and combustion properties of heptane

\begin{tabular}{|l|l|}
\hline Property & Heptane \\
\hline Conductivity, $\lambda(\mathrm{W} / \mathrm{m} . \mathrm{K})$ & 0.17 \\
Heat capacity, $\mathrm{C}_{\mathrm{p}}(\mathrm{kJ} / \mathrm{kg} . \mathrm{K})$ & 684 \\
Pyrolysis heat, $\mathrm{L}_{\mathrm{v}}(\mathrm{kJ} / \mathrm{kg})$ & 321 \\
Combustion heat, $\mathrm{H}_{\mathrm{c}}(\mathrm{kJ} / \mathrm{kg})$ & 44500 \\
Boiling temperature, $\mathrm{T}_{\mathrm{b}}\left({ }^{\circ} \mathrm{C}\right)$ & 98 \\
\hline
\end{tabular}

In a Large Eddy Simulation, turbulence is modelled using a Deardorff's approach [19, 20, 24] via eddy viscosity in which the filter width is attached to the grid size. Since the numerical model uses the quantities that are mesh dependent, a priori estimates of the grid size, $\mathrm{dx}$, are not trivial. A characteristic length of free pool fire $\mathrm{D}^{*}$ is related to HRR, and by using the ratio $\left(D^{*} / \mathrm{dx}\right)$ of 16 [23], the grid size of $5 \mathrm{~cm}$ is estimated for the current enclosure fires. A relatively 
coarse mesh of $10 \mathrm{~cm}$ is usually used in full-scale enclosure fires $[7,19,20]$ for capturing the layered structure of the smoke since it can be resolved using significantly fewer grid points compared to the structure of the flame. The fuel pan of $26 \mathrm{~cm}$ for the high inlet position at 1 and $4 \mathrm{ACPH}$ is selected to examine the required fineness of the grid for this set-up thanks to the experimental data.

Fig.5(a, b) illustrates the predicted HRR and the theoretical one in addition to GER, defined as $\phi=\dot{\mathrm{m}}_{\mathrm{F}} \mathrm{S} / \dot{\mathrm{m}}_{\mathrm{A}}$. The theoretical HRR is derived from the measured MLR, $\dot{\mathrm{m}}_{\mathrm{F}}$.

$$
\dot{\mathrm{Q}}_{\text {the }}=\dot{\mathrm{m}}_{\mathrm{F}} \Delta \mathrm{H}_{\mathrm{c}}
$$

A good agreement is found with the experimental data by using the mesh sizes of 2.5 and $5 \mathrm{~cm}$ for 1 and 4 ACPH. Fig.6(a, b) shows that the appearance and amplitude of the oscillations of radiation flux over the liquid surface are affected by the grid resolution. At $1 \mathrm{ACPH}$, running the simulations on a fine grid of $2.5 \mathrm{~cm}$, the heat flux starts to be over-predicted. It seems that grid size has a negligible effect on the heat flux with an increase of ACPH to 4. During the initial phase before about $100 \mathrm{~s}$, the exaggerated spike of heat flux from the measurements is triggered by the difficulty to measure accurately the liquid depth with an attenuation coefficient which is exponential (Eq.2).

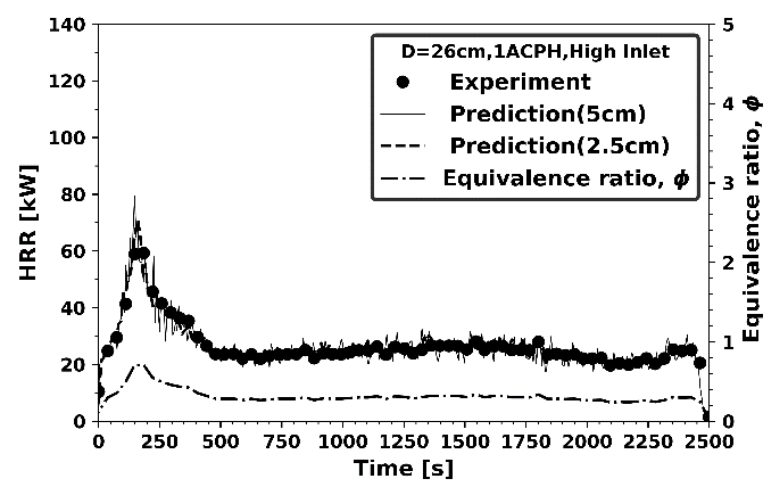

a) at $1 \mathrm{ACPH}$

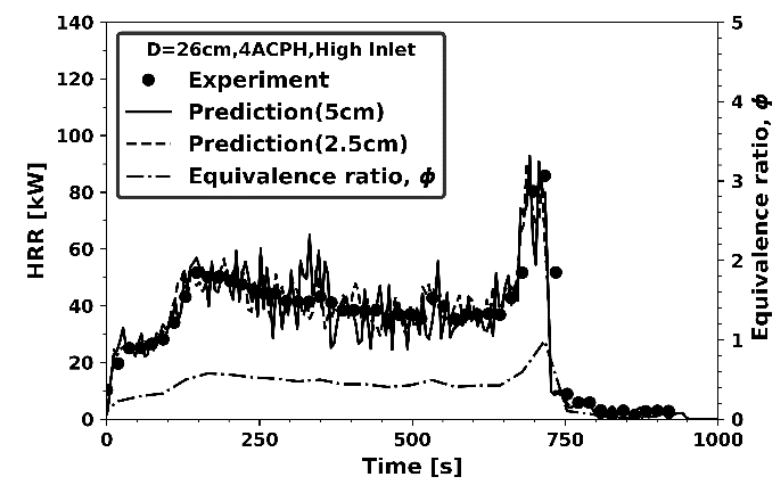

b) at $4 \mathrm{ACPH}$

Figure 5. Influence of the mesh size varying from 5 to $2.5 \mathrm{~cm}$ on the predicted heat release rate

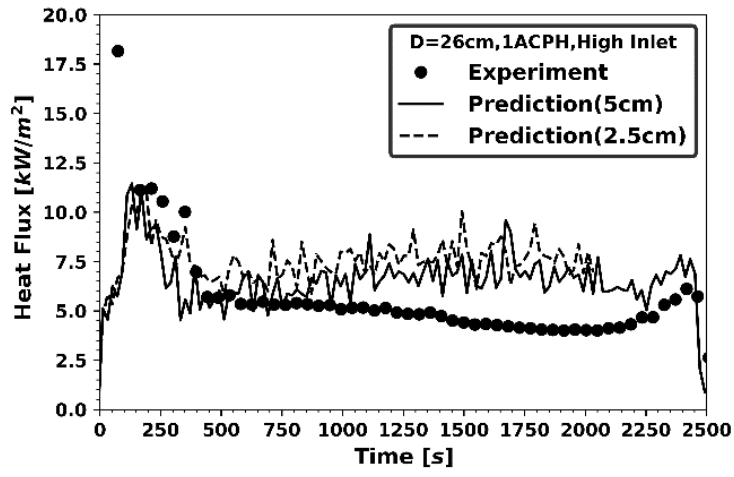

a) at $1 \mathrm{ACPH}$

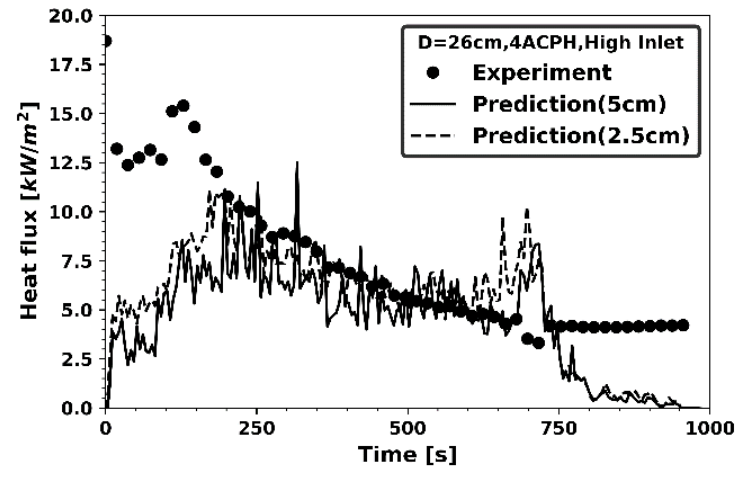

b) at $4 \mathrm{ACPH}$

Figure 6. Influence of the mesh size varying from 5 to $2.5 \mathrm{~cm}$ on the predicted heat flux over the pyrolysis surface

History with time of the predicted oxygen concentration, pressure, velocity and temperature is illustrated only at $1 \mathrm{ACPH}$ since the trend is similar for 4 ACPH (cf. Figs.5b, 6b). Fig.7 demonstrates that over the period of initial phase before $500 \mathrm{~s}$, there is a tendency to over predict oxygen concentration near the fire base when the grid is refined to $2.5 \mathrm{~cm}$. Over the period of steady burning, in comparison with the experimental data, difference in the predicted oxygen 
concentration with the coarse and fine grids remains within 5\%. Fig.8 shows that the overall shape of the temporal evolution of depression level $\left(\mathrm{P}_{0}-\mathrm{P}\right)$ is qualitatively correct even using a coarse grid of $5 \mathrm{~cm}$. Running the simulations on a fine grid of $2.5 \mathrm{~cm}$, amplitude and frequency of the depression oscillations decrease, and the predicted pressure is again far away from the overall experimental data. The time history of inlet flow velocity is examined in Fig.9. The subgrid scale turbulent model even using a mesh size of $2.5 \mathrm{~cm}$ limits the model's capability to predict correctly the inlet velocity. The strong fluctuations of the velocity and pressure were not experimentally detected. A fine grid of $2.5 \mathrm{~cm}$ reduces amplitude and frequency of the velocity oscillations such as for the depression. The time history of gas temperature near the extraction duct is examined in Fig.10. There is a tendency to over predict gas temperature, but the overall shape of the predicted temperature curve is correct by using the two mesh sizes.

Similar trend is found for the other fire conditions with various fuel pan and ACPH. It is illustrated that even a $2.5 \mathrm{~cm}$ cell size is insufficient to ensure the grid independence of all the simulation results. It is found that change of the predicted plots of pressure and velocity in transient mode by using the medium $(5 \mathrm{~cm})$ and fine $(2.5 \mathrm{~cm})$ mesh sizes is higher than $20 \%$. Globally, inside the compartment fire, grid size has a relatively smaller effect on the HRR and temperature by using the experimental burning rate curves as an input. A grid size of $5 \mathrm{~cm}$ can be considered to be enough to reach grid convergence for the prediction of the HRR, oxygen concentration and gas temperature by taking into account the experimental uncertainties. Note that the numerical results with a large mesh size of $10 \mathrm{~cm}$ do not match the measured ones. The computational domain consists of multiple meshes which can be treated with 16 processors through parallel processing of a Linux cluster. With a mesh size of $5 \mathrm{~cm}$, the CPU time for a simulation with a time-step of about $10^{-3} \mathrm{~s}$ during a physical time of $2500 \mathrm{~s}$ is approximately $24 \mathrm{~h}$. With each halving of the grid size, the time required for the simulation increases by a factor of $2^{4}=16$ (a factor of two for each spatial coordinate, plus time). In fact, the criteria $D^{*} / \mathrm{dx}$ [23] for the mesh size optimization is meaningful only for the calculation of the fluid motion outside the flame zone. An extremely small grid size of about $1 \mathrm{~mm}$ is required to fully resolve the characteristic flame thickness close to the fuel pan and turbulent flow instabilities inside enclosure, making practical fire simulations difficult.

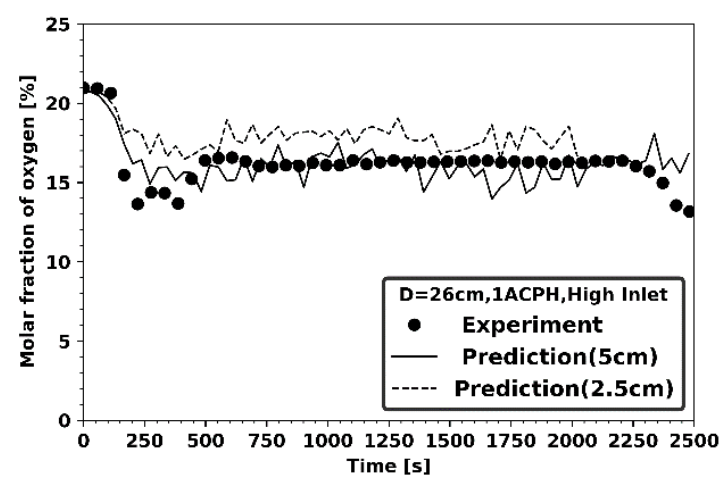

Figure 7. Influence of the mesh size varying from 5 to $2.5 \mathrm{~cm}$ on the predicted oxygen concentration at proximity to fire source at $1 \mathrm{ACPH}$ 


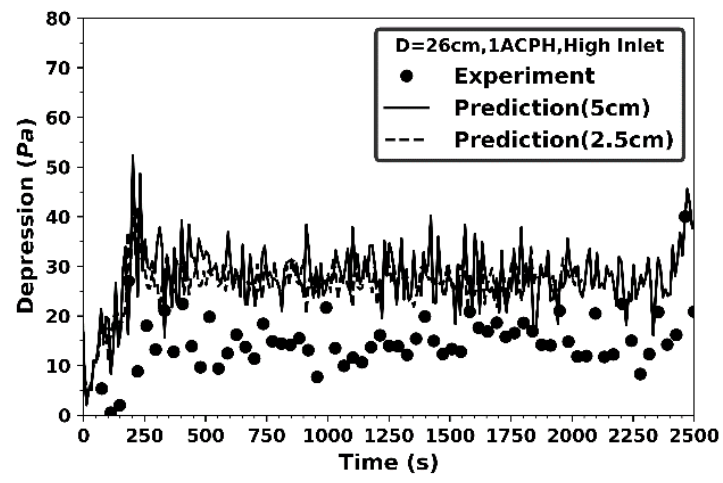

Figure 8. Influence of the mesh size varying from 5 to $2.5 \mathrm{~cm}$ on the predicted pressure at 1 $\mathrm{ACPH}$

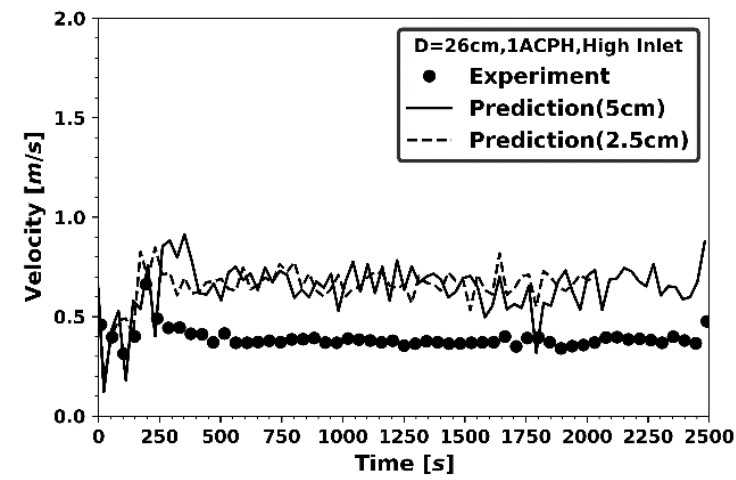

Figure 9. Influence of the mesh size varying from 5 to $2.5 \mathrm{~cm}$ on the predicted inlet flow velocity at $1 \mathrm{ACPH}$

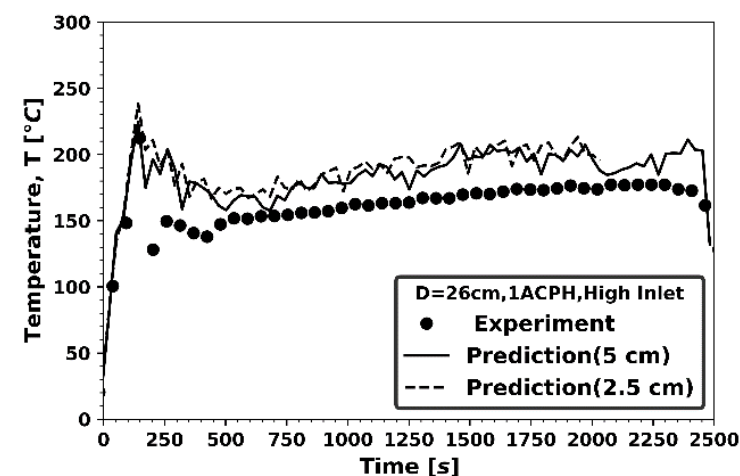

Figure 10. Influence of the mesh size varying from 5 to $2.5 \mathrm{~cm}$ on the predicted gas temperature at entrance of the extraction duct at $1 \mathrm{ACPH}$

\section{RESULTS AND DISCUSSION}

A series of parametric study is performed, allowing to show the effect of air intake position on the behaviour of fires in compartment. We focus on the fire growth rate as well as the resulting pressure, velocity, species, heat flux and temperature in transient mode.

\section{IV.1 Fire dynamics}

Air intake position influences the balance of heat feedback to the liquid fuel and the oxygen available for fire dynamics. Comparison of the numerical results to the measured oxygen concentration outside the fire at $0.3 \mathrm{~m}$ from the pool edge of the flame base (cf. Fig.1c) is 
presented in Figs.11(a-d) and 12(a-d). The predicted oxygen concentration is with an error below $20 \%$ as long as the fire becomes under-ventilated during the fully developed phase. Nevertheless, this analysis allows to check the degree of vitiated air environment surrounding the fire inside enclosure.

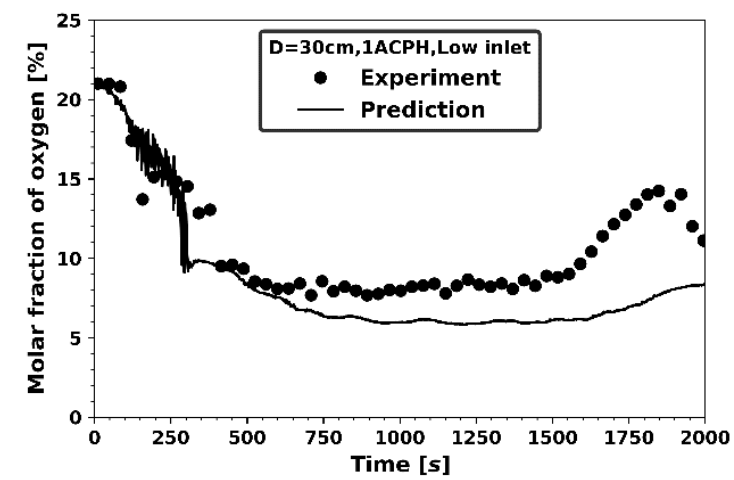

a) Low inlet at $1 \mathrm{ACPH}$

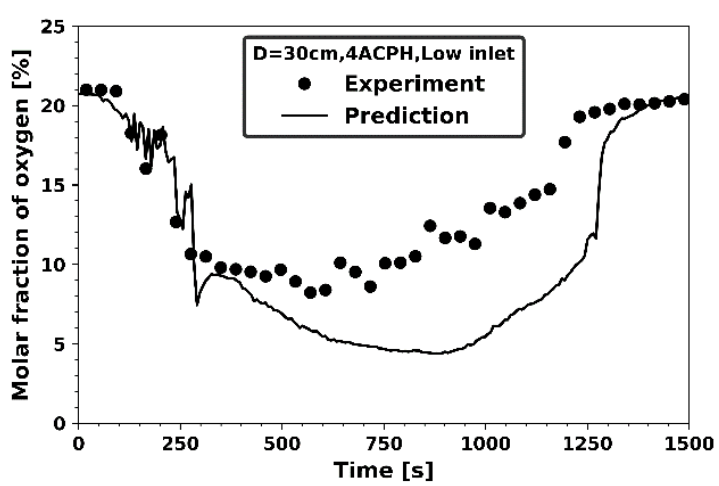

c) Low inlet at $4 \mathrm{ACPH}$

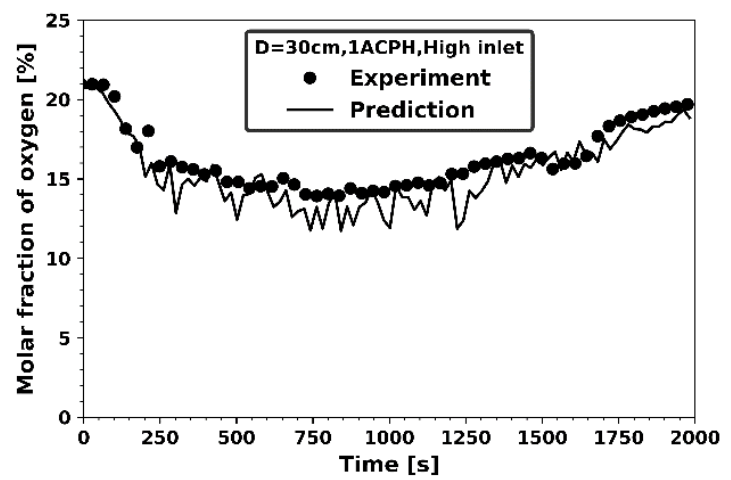

b) High inlet at $1 \mathrm{ACPH}$

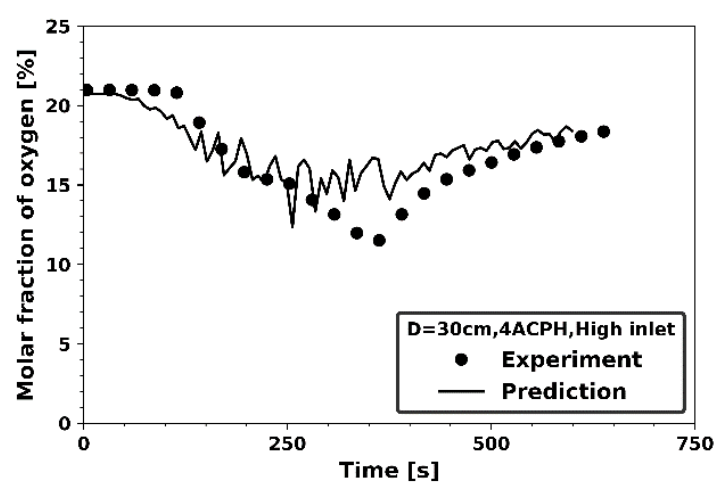

d) High inlet at $4 \mathrm{ACPH}$

Figure 11. Impact of air intake position on the time history of oxygen concentration at proximity to fire source $(0.3 \mathrm{~m})$ for pan diameter of $30 \mathrm{~cm}$.

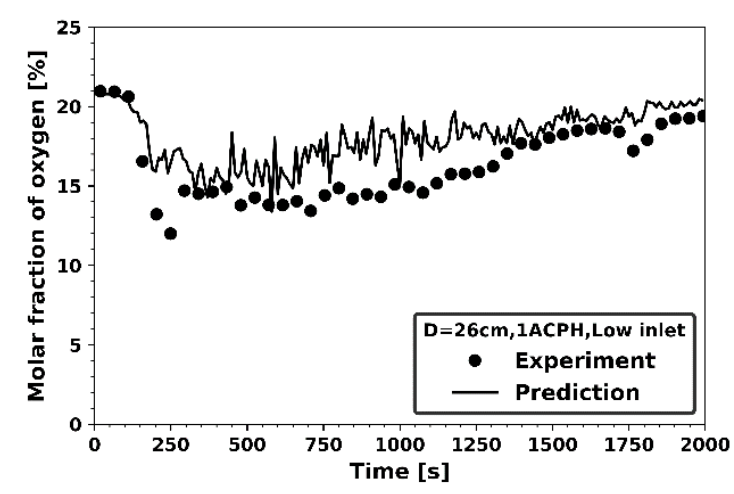

a) Low inlet at $1 \mathrm{ACPH}$

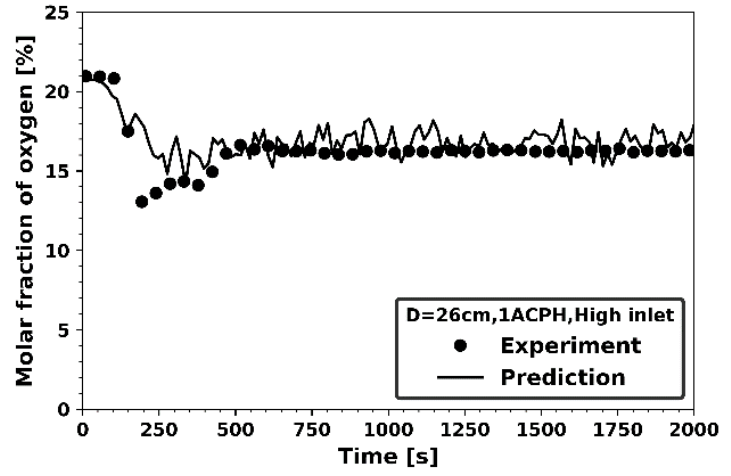

b) High inlet at $1 \mathrm{ACPH}$ 


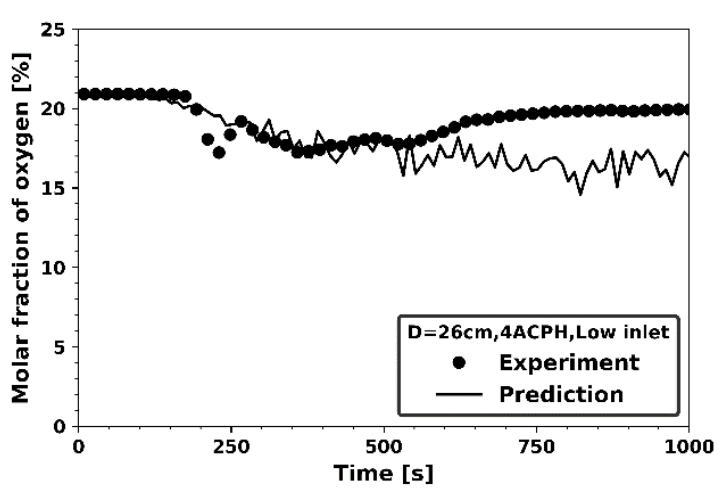

c) Low inlet at $4 \mathrm{ACPH}$

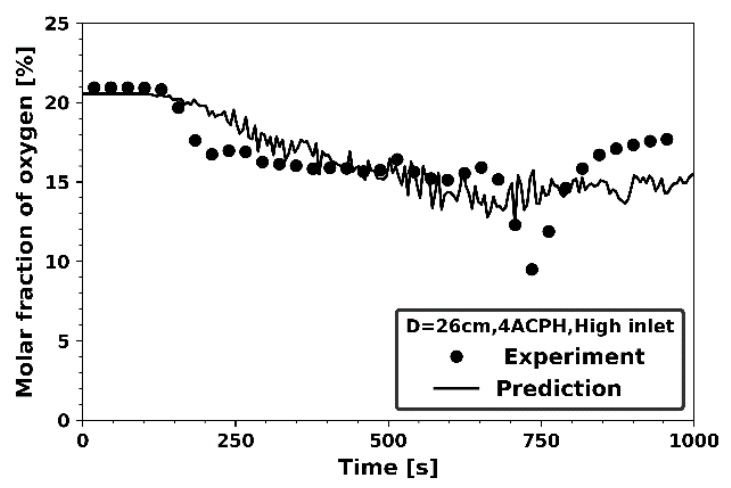

d) High inlet at $4 \mathrm{ACPH}$

Figure 12. Impact of air intake position on time history of oxygen concentration at proximity to fire source $(0.3 \mathrm{~m})$ for pan diameter of $26 \mathrm{~cm}$.

Figs.13(a-d), 15(a, b) and 17a show the temporal evolution of HRR for cases where the air inlet is in low position, and Figs.14(a-d), 16(a, b) and 17b in high position for heptane pans of $D=30$, 26 and $23 \mathrm{~cm}$ at various $\mathrm{ACPH}$ from 1 to 4 . Based on the current study, the value of 0.7 is suggested to identify the fire dynamics regime such as under or over ventilated fire. From the Bryner's work [33], it is found that oxygen concentration above $15 \%$ corresponds to a wellventilated fire with GER below 0.7 ; the range of oxygen concentration between $10 \%$ and $15 \%$ implies an under-ventilated fire with GER between 0.7 and 1. The GER is higher than 1 when oxygen concentration is below $10 \%$, implying a very under-ventilated fire. Indeed, in some cases (cf. Tab.2), the peak value of GER seems to be slightly higher than 0.7 even for an overventilated fire, probably due to the uncertainties in both the measurement and calculation. The compartment fire dynamics as a function of GER can be said to follow three main stages, such as initial, fully developed and decaying phases.

During the initial period, regardless of air intake position, the oxygen amount surrounding the flame base with a concentration above $15 \%$ is maintained (cf. Figs.11, 12). The availability of sufficient oxygen, initially present in the compartment and supplied by ventilation flow, allows the pyrolysis gases to undergo gas-phase combustion rapidly, characterized by a sharp rise of HRR up to reaching a maximum. A large amount of energy is released in the form of radiation, and as a result, the heat feedback from the gaseous flame increases the pyrolysis rate of liquid fuel. By assuming a quadratic growth for the various fire scenarios, an empirical formula [34] can be adopted as follows:

$$
\dot{\mathrm{Q}}=\mathrm{at}^{2}
$$

The early fire growth factor, a, is defined as $10^{3} \mathrm{~kW} / \mathrm{t}_{1}{ }^{2}$. The growth time, $\mathrm{t}_{1}$, is approximately $600 \mathrm{~s}$, corresponding to a slow fire growth. For the fuel pan of $30 \mathrm{~cm}$ (cf. Fig.14), the HRR reaches a peak value of only $60 \mathrm{~kW}$ by placing air intake in high position. Changing air intake position from high to low leads to an ultra-fast fire growth, which is clearly identified by a rapid increase of HRR to a peak value of $100 \mathrm{~kW}$ (cf. Fig.13b-d). A reduction in the fuel pan size from $30 \mathrm{~cm}$ (cf. Fig.13) to $23 \mathrm{~cm}$ (cf. Fig.17) conducts to a decrease in the HRR peak.

Starting from about $250 \mathrm{~s}$, oxygen initially present in the compartment $\left(8 \mathrm{~m}^{3}\right)$ is consumed, and this is followed by a fire decaying or exhaust phase with a slow decrease of HRR even if it remains fuel in the pan. This is mainly attributed to the presence of two competing fire interaction mechanisms : heat feedback enhancement to pyrolysis surface and heat evacuation by mechanical ventilation. During fire exhaust phase due to lack of oxygen, the heat evacuation 
through a mechanical ventilation via the extraction duct is inferior to the amount of energy released during combustion. A fire exhaust helps to reduce the heat feedback to the liquid fuel surface due to cooling effects, conducting to a reduction in MLR. Particularly in underventilated conditions, changing air intake position from low to high change significantly the fire dynamics. For fuel pan of $30 \mathrm{~cm}$ at $1 \mathrm{ACPH}$, the HRR curves show a decreasing trend from a peak value of about $70 \mathrm{~kW}$ for a low inlet (cf. Fig.13a) and of $60 \mathrm{~kW}$ for a high inlet (cf. Fig.14a). With an increase of ACPH from 2 to 4, the amount of oxygen supplied from a low inlet contributes to a rise of the HRR peak from $70 \mathrm{~kW}$ (cf. Fig.13b) to $90 \mathrm{~kW}$ (cf. Fig.13d), followed by a quasi steady state period. However, a rise of $\mathrm{ACPH}$ in high position helps to generate the cooling effects on the ceiling hot smoke layer, and the fire growth rate is controlled by how fast the pyrolysis rate of liquid fuel via heat feedback. Fig.14(a-d) shows that the maximum HRR for a high inlet is practically insensitive to an increase of ACPH from 1 to 4 with a value of about $65 \mathrm{~kW}$. A stronger HRR at $4 \mathrm{ACPH}$ for a low inlet (cf. Fig.13d) conducts to a decrease of oxygen concentration to 7\% (cf. Fig.11c), and a lower HRR for a high inlet (cf. Fig.14d) improves air vitiation environment surrounding the fire with an oxygen concentration of $13 \%$ (cf. Fig.11d). Usually, the oxygen concentration surrounding the fire for a high inlet is greater than that for a low inlet. It is found that fire dynamics become less sensitive to air intake position for well-ventilated fires, such as for the fuel pan of $23 \mathrm{~cm}$ (cf. Fig.17a, b) due to sufficient quantity of oxygen for intensive combustion.

In under-ventilation conditions, with low air intake, fire from a fuel pan of $30 \mathrm{~cm}$ stops due to a lack of oxygen (cf. Fig.13). When the air admission is placed in high position (cf. Fig.14), fire exhaust occurs due to a decreasing contribution of the radiation heat flux to the degradation of condensed fuel into pyrolysis gases. Because oxygen concentration is above 13\% (cf. Fig.11b, d) which is higher than the Minimum Oxygen Concentration for oxidation of $\mathrm{CO}$ to $\mathrm{CO}_{2}$ [31]. The fire exhaust happens earlier for high inlet position (cf. Fig.14b-d), resulting in a reduction in fire duration from 2000 to $500 \mathrm{~s}$ with an increase of ACPH from 2 to 4 . Fire extinction for the fuel pan below $26 \mathrm{~cm}$ (cf. Fig. 17) is mainly due to a lack of fuel. A fire decaying favours an improvement of air vitiation environment surrounding the fire, identified by a slow increase in oxygen concentration (cf. Figs.11, 12). An accumulation of oxygen in the compartment is mainly involved by mechanical ventilation. Leakages through the enclosure envelope also contribute to an accumulation of oxygen outside the fire even they does not directly participate in the ventilation of the fuel pan.

In Fig.13(a-d), the curves with labels as Experiment show the theoretical HRR which is derived from the measured MLR (Eq.7) without taking into account gas-phase combustion. The oscillations of predicted HRR from 20 to $100 \mathrm{~kW}$ for low inlet (cf. Fig.13b-d) are caused by an interplay of the combustion model and the ventilation. This is why the oscillations occur in the simulations, when the experimental results (theoretical HRR) show no oscillation. Nevertheless, this oscillating phenomenon follows the trend of the previous works [13,14] due to ghosting flame where the flame moves from the fuel pan, expanding radially and horizontally towards the zone with oxygen availability. The combustion efficiency is determined from the ratio between the effective (Eq.5) and the measured theoretical HRR (Eq.7), expressed as $\eta=\dot{\mathrm{Q}}_{\text {eff }} / \dot{\mathrm{Q}}_{\text {the }}$. For the pan of $30 \mathrm{~cm}$, when growing fire becomes progressively oxygen limited with a GER close to 1, the theoretical HRR is higher than the predicted one (cf. Fig.13). Thus, burning heptane pan of $30 \mathrm{~cm}$ for low inlet position (cf. Fig.13) corresponds to under-ventilated fire with a drastic decrease in combustion efficiency up to about 0.5 due to production of a nonnegligible quantity of unburnt fuel [9]. For the same pan of $30 \mathrm{~cm}$, changing air intake position from low to high leads to an over-ventilated fire with a GER below 0.8, and the combustion efficiency reaches almost to 1 . For heptane pans below or equal to $26 \mathrm{~cm}$ (cf. Figs.15, 16, 17), 
the HRR reproduced by the oxygen limited combustion model (Eq.5) follows closely the theoretical one with good accuracy. This implies that the air supply rate from mechanical ventilation is sufficient to entrain an intensive burning with a GER below 0.7, resulting in a combustion efficiency close to 1 . Table 2 describes in details the experiments and simulations conducted to identify an under or over ventilated fire.

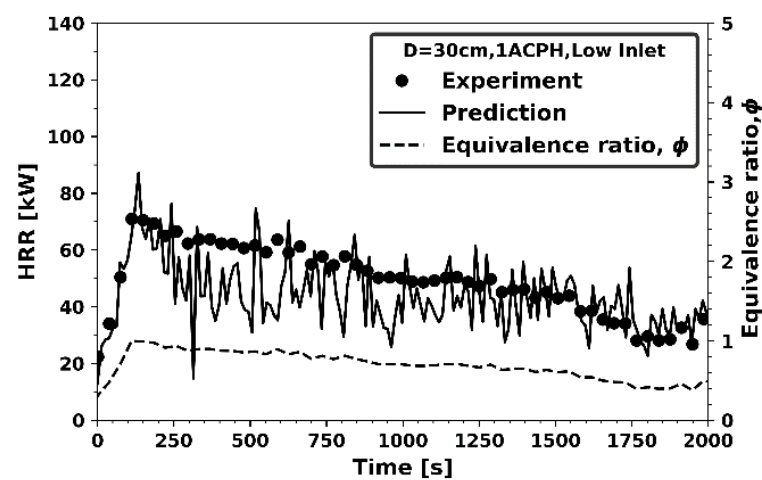

a) $1 \mathrm{ACPH}$

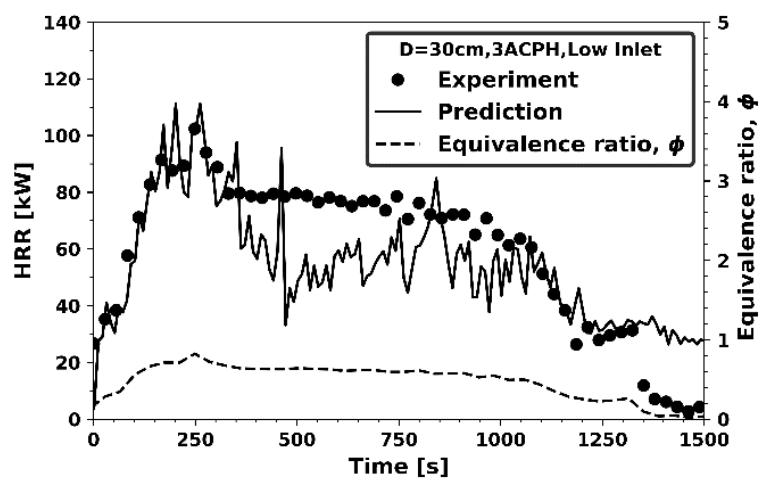

c) $3 \mathrm{ACPH}$

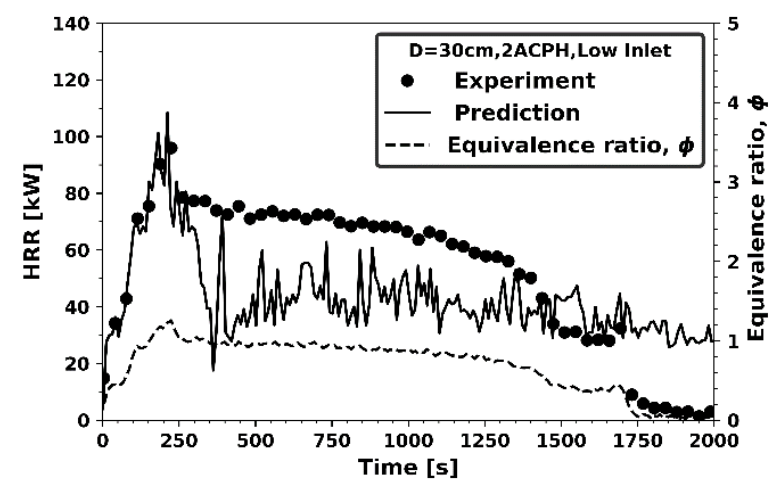

b) $2 \mathrm{ACPH}$

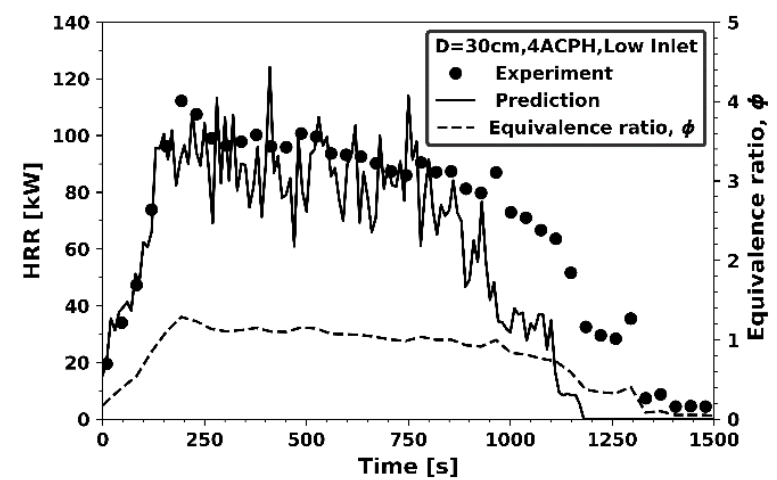

d) $4 \mathrm{ACPH}$

Figure 13. Evolutions of the theoretical HRR (Experiment) and the effective one (Prediction) for pan diameter of $30 \mathrm{~cm}$ with air admission in low position.

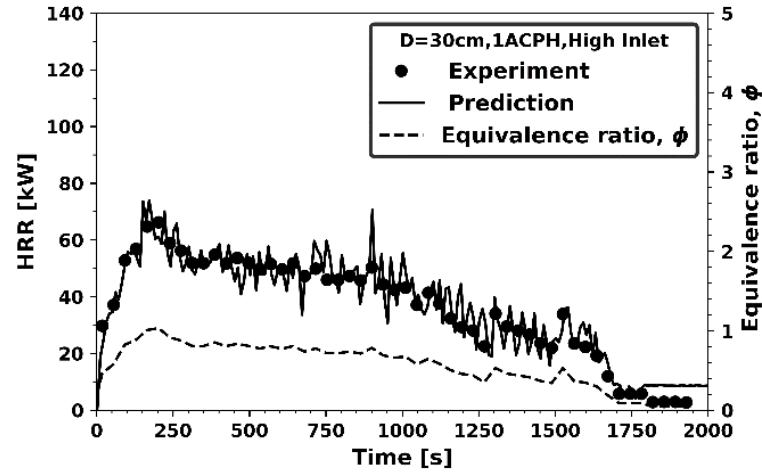

a) $1 \mathrm{ACPH}$

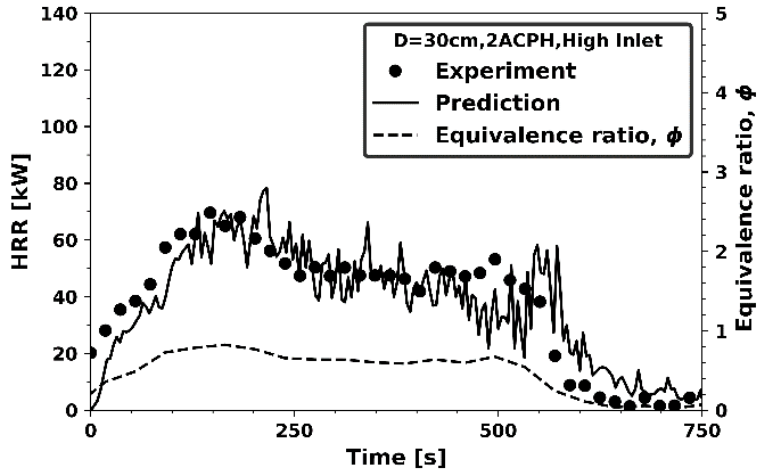

b) $2 \mathrm{ACPH}$ 


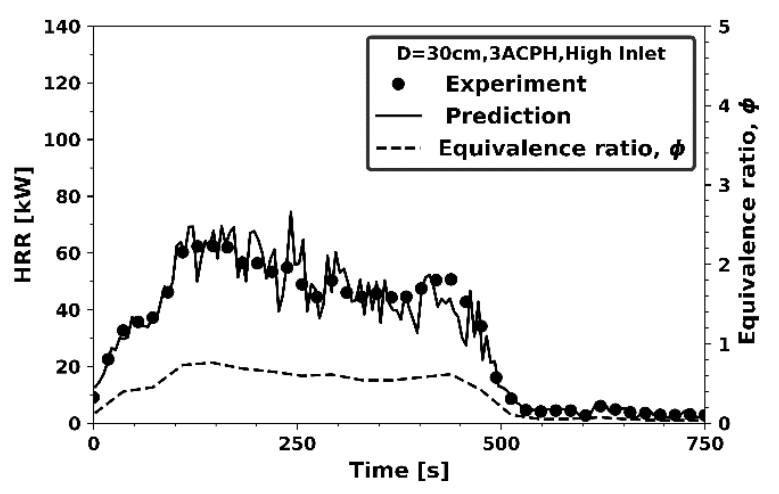

c) $3 \mathrm{ACPH}$

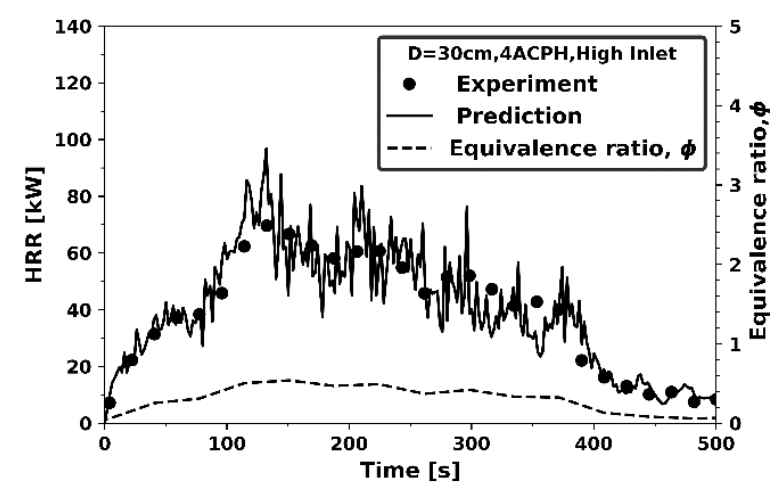

d) $4 \mathrm{ACPH}$

Figure 14. Evolutions of the theoretical HRR (Experiment) and the effective one (Prediction) for pan diameter of $30 \mathrm{~cm}$ with air admission in high position

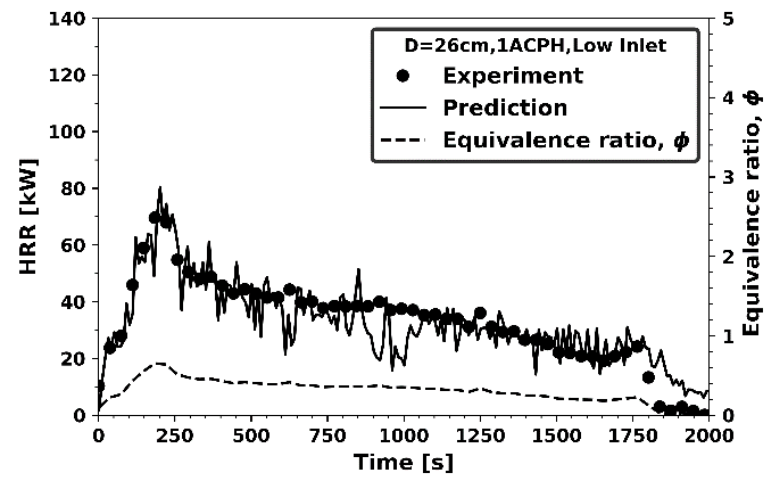

a) $1 \mathrm{ACPH}$

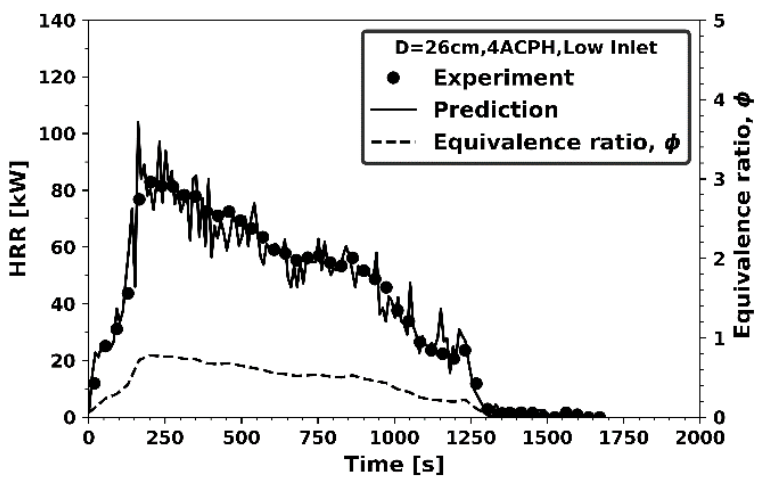

b) $4 \mathrm{ACPH}$

Figure 15. Evolutions of the theoretical HRR (Experiment) and the effective one (Prediction) for pan diameter of $26 \mathrm{~cm}$ with air admission in low position.

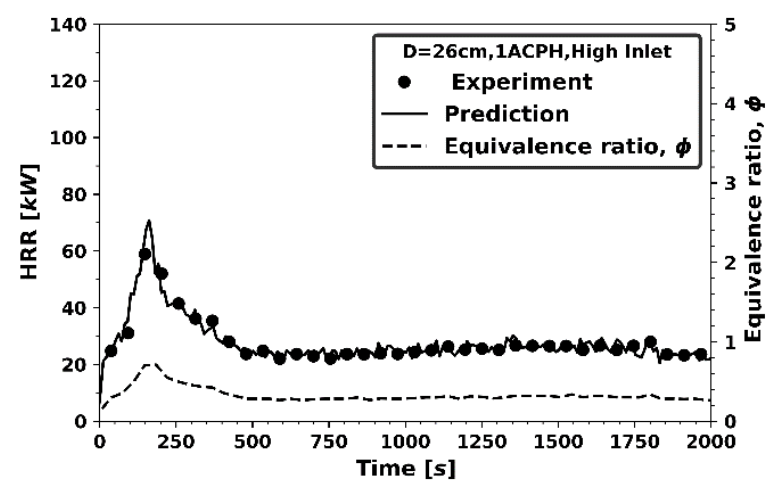

a) $1 \mathrm{ACPH}$

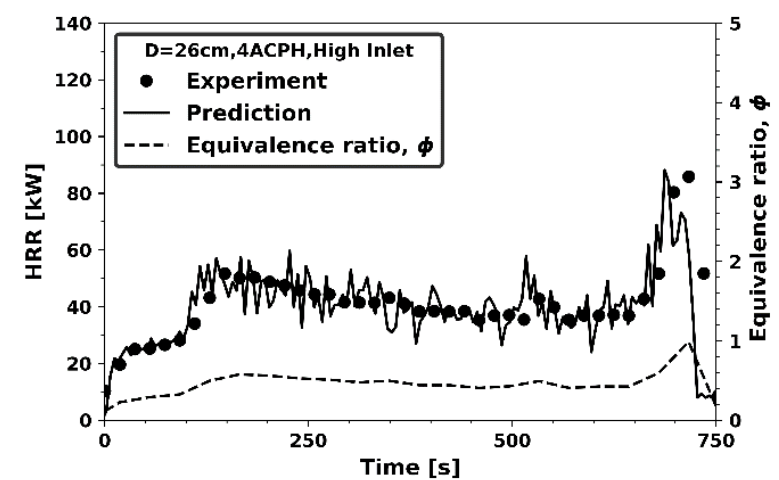

b) $4 \mathrm{ACPH}$

Figure 16. Evolutions of the theoretical HRR (Experiment) and the effective one (Prediction) for pan diameter of $26 \mathrm{~cm}$ with air admission in high position 


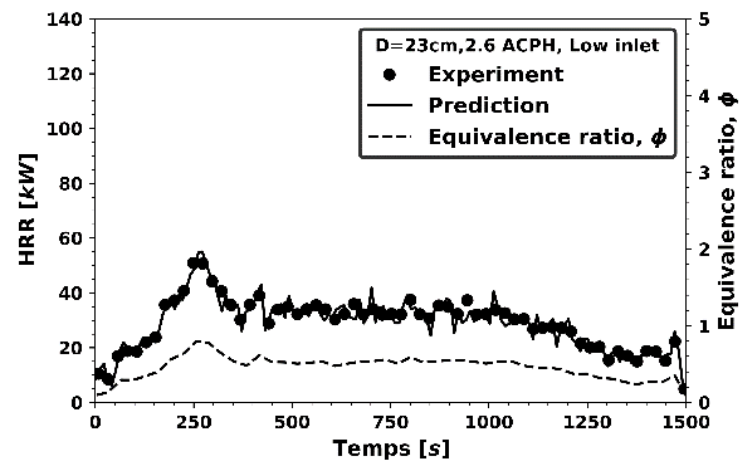

a) with low inlet

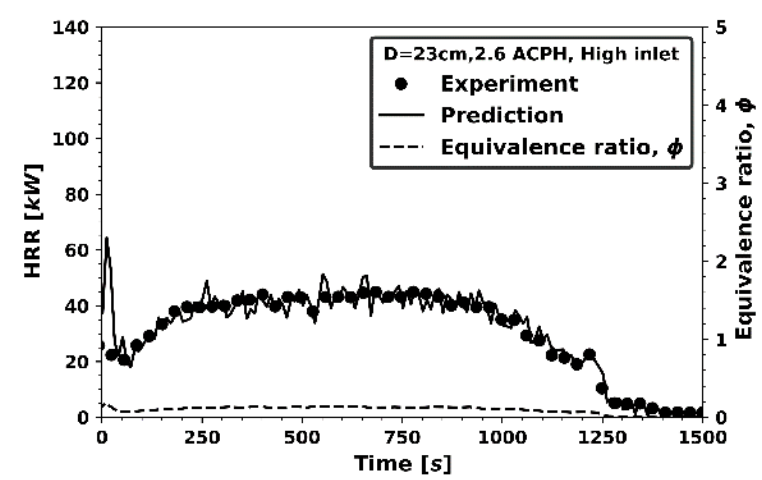

b) with high inlet

Figure 17. Evolutions of the theoretical HRR (Experiment) and the effective one (Prediction) for pan diameter of $23 \mathrm{~cm}$

Table 2. Information regarding the conducted experiments and simulations

\begin{tabular}{|l|l|l|l|l|l|}
\hline Fuel pan & ACPH & $\begin{array}{l}\text { Air intake } \\
\text { position }\end{array}$ & $\begin{array}{l}\text { Equivalence } \\
\text { ratio }\end{array}$ & $\begin{array}{l}\text { Combustion } \\
\text { efficiency }\end{array}$ & Fire regime \\
\hline $23 \mathrm{~cm}$ & 2.6 & Low & $0.1<\phi<0.7$ & $\eta \approx 1$ & Over ventilated \\
\hline $23 \mathrm{~cm}$ & 2.6 & High & $0.1<\phi<0.2$ & $\eta \approx 1$ & Over ventilated \\
\hline $26 \mathrm{~cm}$ & $1-4$ & Low & $0.1<\phi<0.8$ & $\eta \approx 1$ & Over ventilated \\
\hline $26 \mathrm{~cm}$ & $1-4$ & High & $0.1<\phi<0.8$ & $\eta \approx 1$ & Over ventilated \\
\hline $30 \mathrm{~cm}$ & 1 & Low & $0.4<\phi<1$ & $\eta \approx 0.7$ & Under ventilated \\
\hline $30 \mathrm{~cm}$ & 2 & Low & $0.1<\phi<1$ & $\eta \approx 0.5$ & Under ventilated \\
\hline $30 \mathrm{~cm}$ & 3 & Low & $0.4<\phi<0.8$ & $\eta \approx 0.5$ & Under ventilated \\
\hline $30 \mathrm{~cm}$ & 4 & Low & $0.1<\phi<1.2$ & $\eta \approx 0.5$ & Under ventilated \\
\hline $30 \mathrm{~cm}$ & $1-3$ & High & $0.1<\phi<0.8$ & $\eta \approx 1$ & Over ventilated \\
\hline $30 \mathrm{~cm}$ & 4 & High & $0.1<\phi<0.6$ & $\eta \approx 1$ & Over ventilated \\
\hline
\end{tabular}

\section{IV.2 Fire-induced pressure and velocity field}

The scenario of a fire in a confined and ventilated enclosure is a typical hazard during which the pressure may vary to extent where it modifies the confinement levels and hence the safety of the installation. Temporal evolution of the depression level $\left(\mathrm{P}_{0}-\mathrm{P}\right)$ inside the enclosure is analyzed in Fig.18(a-d) for $\mathrm{D}=30 \mathrm{~cm}$ at 1 and 4 ACPH. The evolution of depression inside enclosure is shown to depend strongly on the fire development associated with the air intake position. For the high inlet, a rise of ACPH from 1 to 4 is found to enhance the expected peak depression level from 30 to $45 \mathrm{~Pa}$ due to a decrease in HRR (cf. Fig.14). For the low inlet, an increase of ACPH from 1 to 4 tends to reduce the depression peak from 40 to $30 \mathrm{~Pa}$ (cf. Fig.18b, d) due to an augmentation of HRR (cf. Fig.13). The prediction is lower than the measured depression level, and the deviation of the numerical results in relation to experimental data is more than 3 times. 


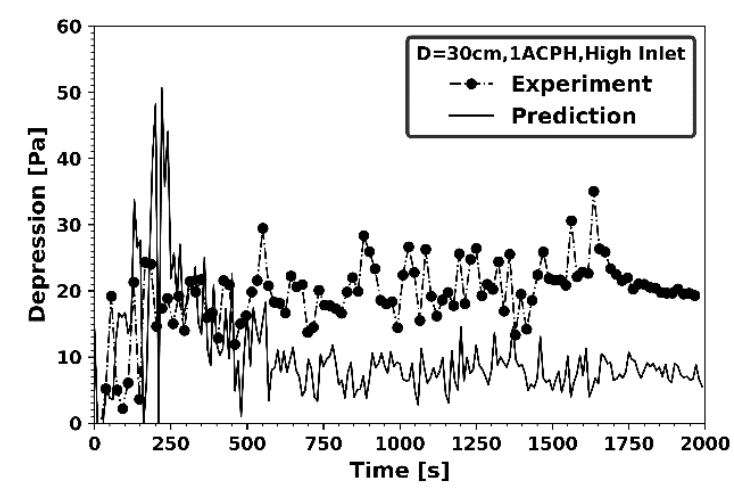

a) High inlet position at $1 \mathrm{ACPH}$

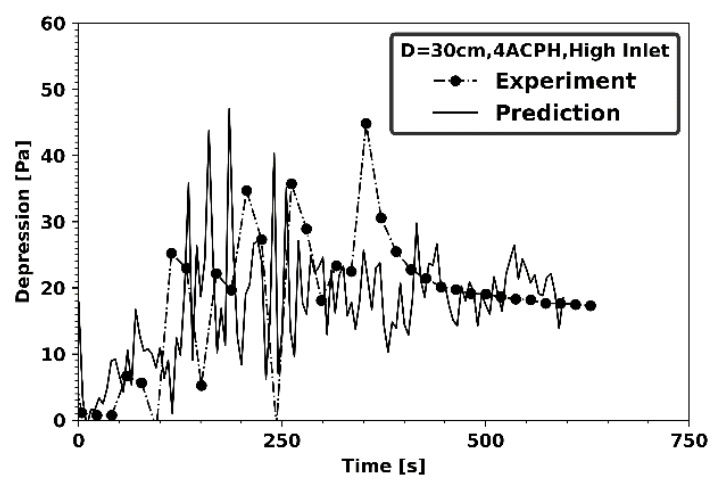

c) High inlet position at $4 \mathrm{ACPH}$

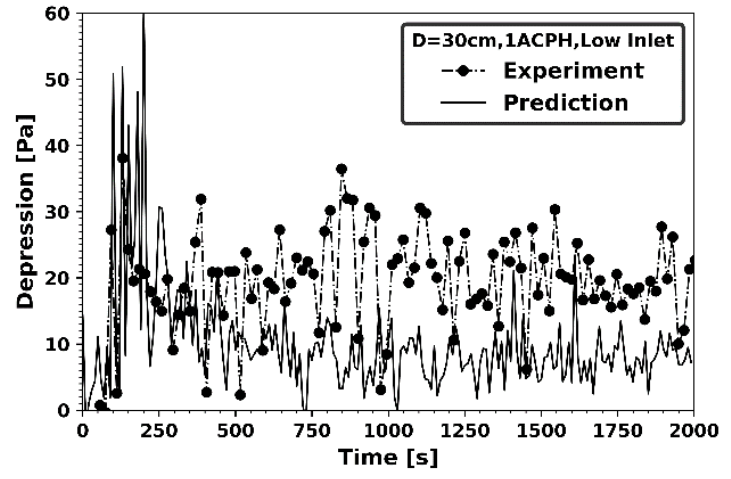

b) Low inlet position at $1 \mathrm{ACPH}$

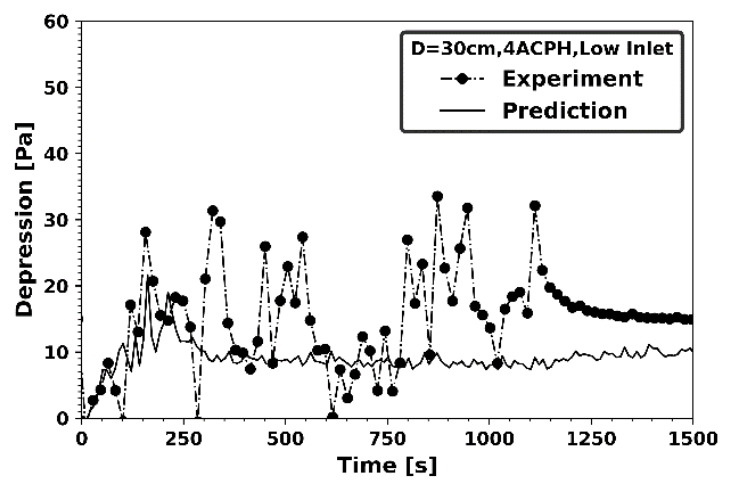

d) Low inlet position at $4 \mathrm{ACPH}$

Figure 18. Evolution of the compartment fire pressure for pan diameter of $30 \mathrm{~cm}$.

Evolution with time of the inlet flow velocity from admission duct thanks to the compartment depression is illustrated in Fig.19(a-d) for the same pan $(D=30 \mathrm{~cm})$. The air inlet velocity in absence of the fire was measured in a range from $0.1 \mathrm{~m} / \mathrm{s}$ at $1 \mathrm{ACPH}$ to $0.27 \mathrm{~m} / \mathrm{s}$ at $4 \mathrm{ACPH}$, depending on the compartment depression level. In the numerical simulations, activating the fire causes a rapid decrease in the depression level (cf. Fig.18), and as a result, a significant reduction in the inlet flow velocity. With some time delay, appearance of the velocity oscillations is attributed to the fluctuations of the compartment fire pressure, particularly with a high ACPH of 4 . This results in a faster inlet flow with a peak velocity up to $4.3 \mathrm{~m} / \mathrm{s}$ instead of $0.5 \mathrm{~m} / \mathrm{s}$ at $1 \mathrm{ACPH}$. The supply rate of fresh air from admission duct at $1 \mathrm{ACPH}$ is practically independent of a change of air intake position from high to low. However, at $4 \mathrm{ACPH}$, a change of air intake position from high to low conducts to a decrease in the inlet velocity from 4 to 3.4 $\mathrm{m} / \mathrm{s}$ (cf. Fig.19c, d) due to a reduction in depression level (cf. Fig.18c, d). The characteristic dependence between the depression level (cf. Fig.18) and the inlet air flow rate (cf. Fig.19) is qualitatively captured by the models for most simulations. The measured high spikes of the inlet velocity at 4 ACPH (cf. Fig.19c, d) are significantly under-predicted, and the deviation of the numerical results in relation to experimental data is more than 2 times. The HVAC module [32] seems incapable of calculating the overall oscillation of the depression and inlet velocity, which requires knowledge of the complex turbulent flow instabilities inside enclosure. 


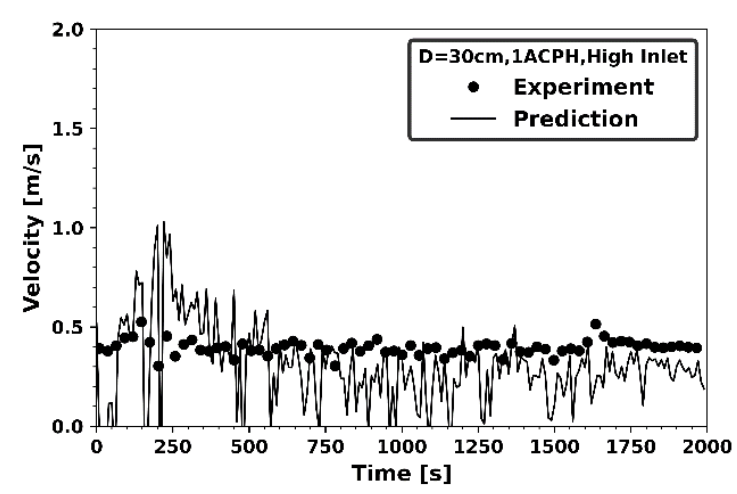

a) High inlet position at $1 \mathrm{ACPH}$

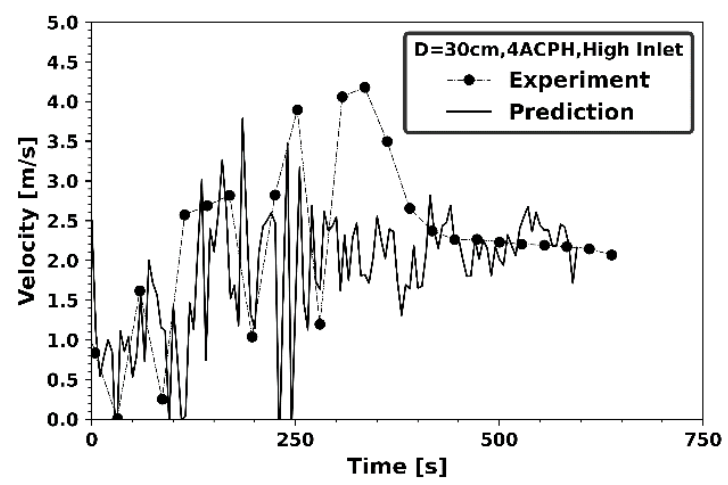

c) High inlet position at $4 \mathrm{ACPH}$

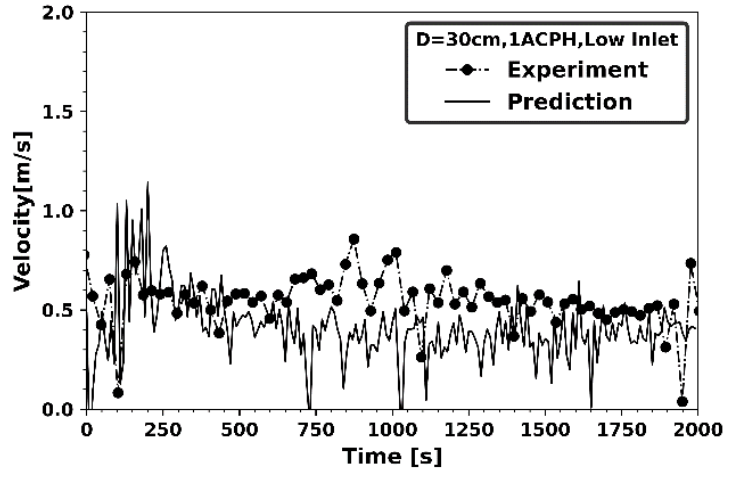

b) Low inlet position at $1 \mathrm{ACPH}$

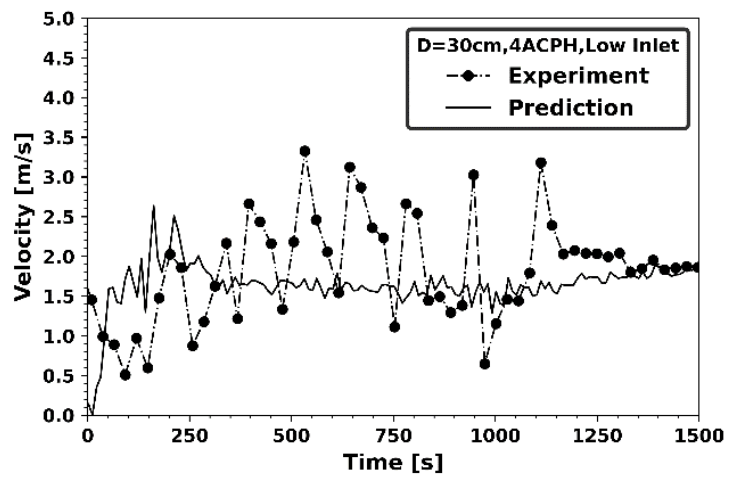

d) Low inlet position at $4 \mathrm{ACPH}$

Figure 19. Evolution of the inlet velocity from the admission duct for pan diameter of $30 \mathrm{~cm}$.

The general instantaneous flow circulation at $\mathrm{t}=250 \mathrm{~s}$ inside the compartment is qualitatively illustrated in Fig.20(a, b) for a fuel pan of $30 \mathrm{~cm}$ at 4 ACPH. Regardless of air intake position, large recirculations are formed between the top and the floor. With a low inlet, the horizontal velocity allows to bring more oxygen close to the pool fire. Consequently, combustion is more intensive with an enhanced effective HRR (cf. Fig.13d), allowing a greater heat feedback from the flame to facilitate a faster burning of liquid fuel. The air jet in high position is orthogonal to the buoyancy-induced flow above the fire base (cf. Fig.20b), restricting air supply into the pool fire base. Fresh air in high position significantly disturbs the smoke layer structure near the ceiling and the vertical buoyancy-induced flow. As a result, air jet in high position leads to a reduction in HRR (cf. Fig.14d) due to a cooling effect on the hot smoke layer affecting burning rate of liquid fuel via radiation heat feedback. 


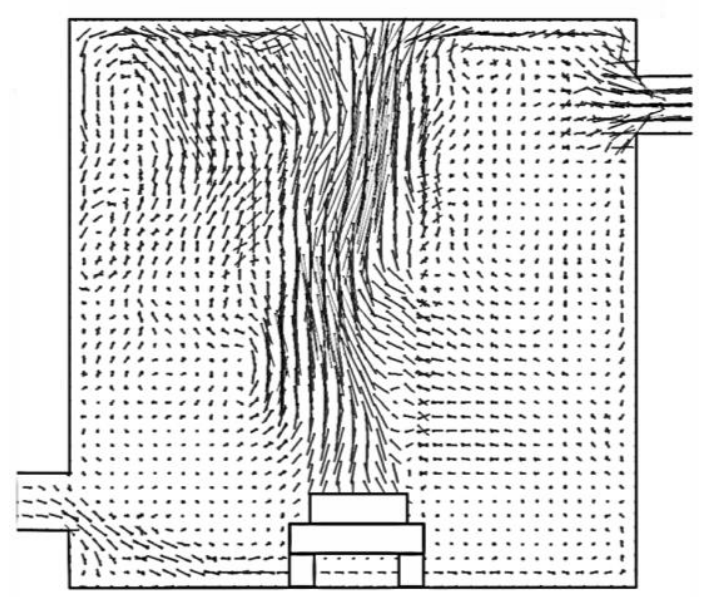

a) Air intake in low position

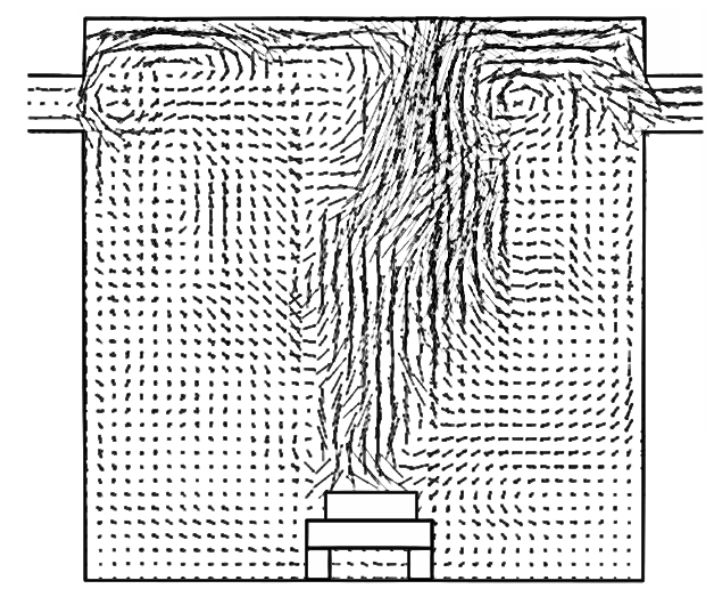

b) Air intake in high position

Figure 20. Instantaneous flow circulation inside the compartment for fuel pan of $30 \mathrm{~cm}$ at 4 ACPH with a maximum velocity of $4.5 \mathrm{~m} / \mathrm{s}$

\section{IV.3 Thermal field and heat flux}

The fuel pan of $30 \mathrm{~cm}$ in diameter is selected to illustrate the influence of air intake position on thermal field. The temperature profiles along the vertical center line TC and right line TR (cf. Fig.1c) at two instants of 250 and $500 \mathrm{~s}$ for 1 and 4 ACPH are illustrated in Figs.21(a-d) and 22(a-d). Regardless of air intake position at $1 \mathrm{ACPH}$, the temperature profiles at $250 \mathrm{~s}$ (cf. Fig.21a) and $500 \mathrm{~s} \mathrm{(cf.} \mathrm{Fig.21b)} \mathrm{are} \mathrm{practically} \mathrm{identical.} \mathrm{This} \mathrm{implies} \mathrm{that} \mathrm{a} \mathrm{steady} \mathrm{state} \mathrm{inside}$ enclosure happens earlier starting from $250 \mathrm{~s}$. Air admission at low ACPH of 1 helps to maintain a hotter smoke layer near the ceiling with a temperature level of about $250^{\circ} \mathrm{C}$. For a high $\mathrm{ACPH}$ of 4 , a low inlet conducts to a rapid fire growth with an increase of the smoke temperature near the ceiling from 250 to $350^{\circ} \mathrm{C}$ when the upper smoke layer is established at $500 \mathrm{~s}$ (cf. Fig.21c, d). While as, for a high air intake at $4 \mathrm{ACPH}$, the compartment behaves as a well-stirred reactor at $500 \mathrm{~s}$ with a smoke temperature of about $50^{\circ} \mathrm{C}$ (cf. Fig.21d) due to fire exhaust (cf. Fig.14d). This implies that the smoke temperature over the pyrolysis surface with a low inlet is about 7 times higher than the one with a high inlet at $4 \mathrm{ACPH}$. The prerequisites for the ultra-fast consistent fire growth (cf. Fig.13) with a low inlet are a higher smoke temperatures $\left(>250^{\circ} \mathrm{C}\right)$ to enhance heat feedback for the thermal degradation of liquid fuel. Outside the flame zone along the line TR (cf. Fig.1c), there is a good fit between the predicted and measured smoke temperature (cf. Fig.22a-d). Regarding the gas temperature field above the flame base (cf. Fig.21) in transient mode at $\mathrm{t}=500 \mathrm{~s}$ (cf. Fig.21b, d), the profiles, in turn, are not captured as well with a deviation of 5 times in relation to the measurement. In comparison with the measured temperature, the prediction is better with low air admission than that with high air admission. The shortcoming of the use of a fast EDC combustion model [24] is irrespective to the chemical kinetic depending on the gas temperature. Contrary to the experimental results, the relationship between predicted temperature and height is not monotonous. This implies that the numerical model is incapable of reproducing the complex turbulent flow circulations inside the compartment. This seems also most likely due to the coupling effect between pressure variations and oxygen feedings through the inlet. When the numerical model reproduces a lower pressure difference (cf. Fig.18) between inside and outside, less air is introduced (cf. Fig.19), resulting in a reduction both in the HHR and temperature inside the compartment. Inversely, an over-predicted pressure difference induces more air, and as a result, an increase of the HRR conducts to an augmentation of the smoke temperature. 


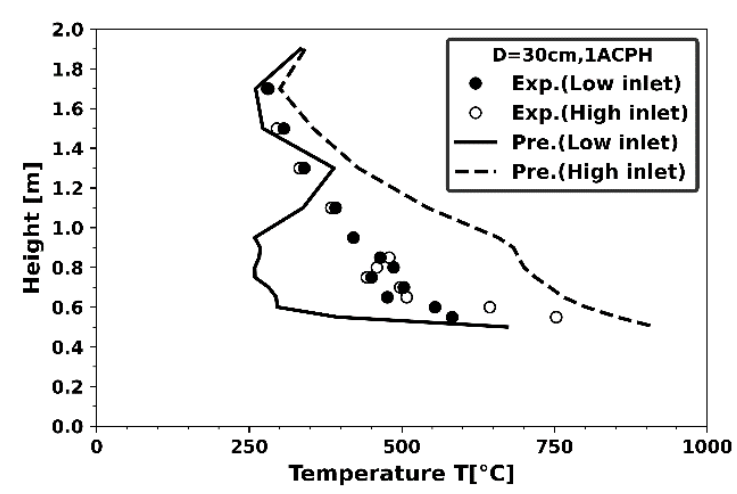

a) $1 \mathrm{ACPH}$ at $\mathrm{t}=250 \mathrm{~s}$

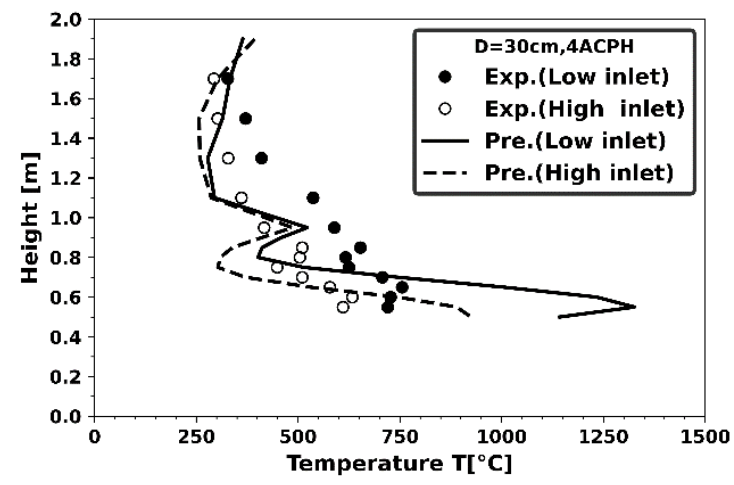

c) $4 \mathrm{ACPH}$ at $\mathrm{t}=250 \mathrm{~s}$

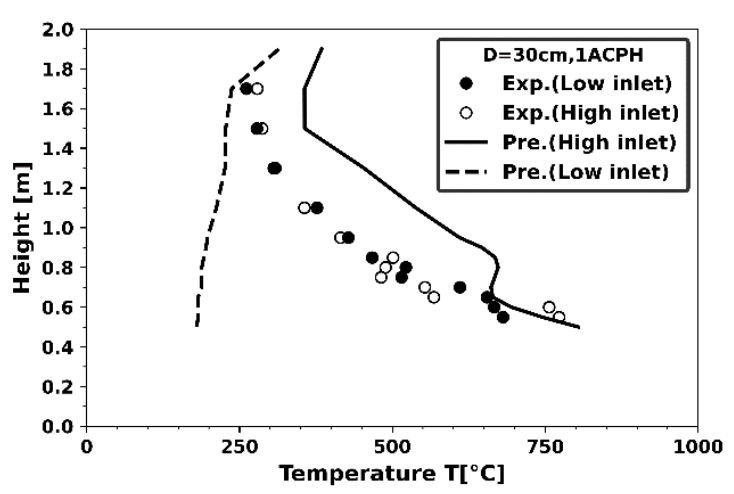

b) $1 \mathrm{ACPH}$ at $\mathrm{t}=500 \mathrm{~s}$

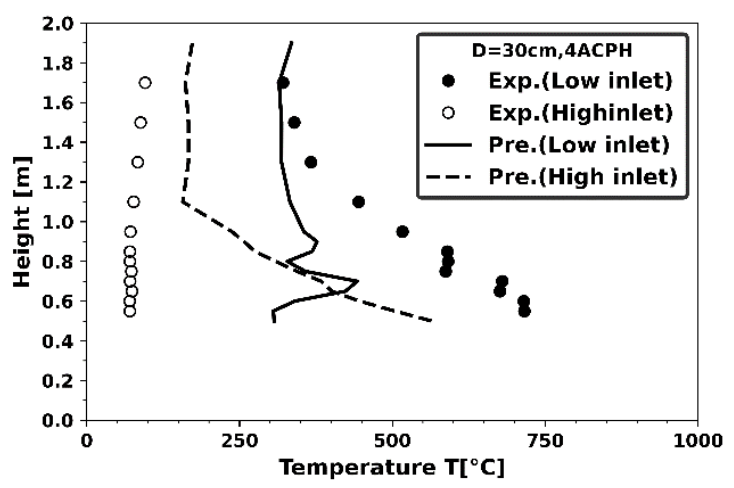

d) $4 \mathrm{ACPH}$ at $\mathrm{t}=500 \mathrm{~s}$

Figure 21. Influence of air intake position on the time history of gas-phase temperature in the center of the compartment (TC1-8) for pan diameter of $30 \mathrm{~cm}$.

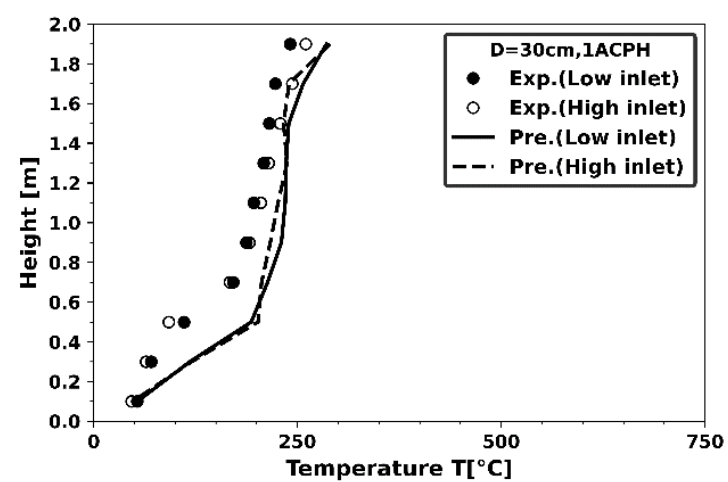

a) $1 \mathrm{ACPH}$ at $\mathrm{t}=250 \mathrm{~s}$

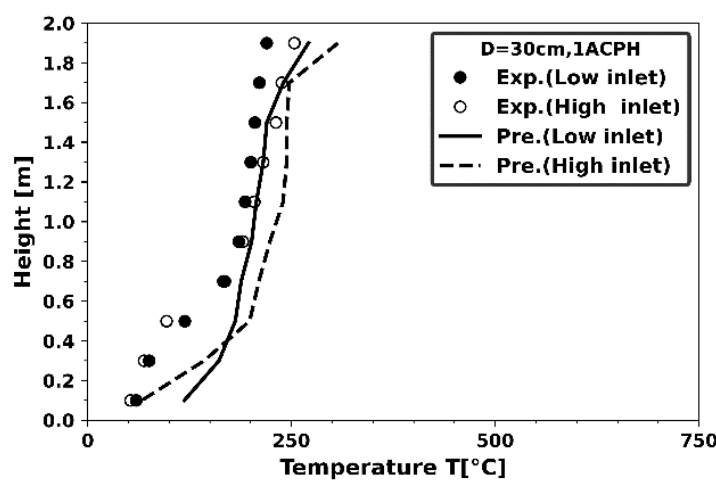

b) $1 \mathrm{ACPH}$ at $\mathrm{t}=500 \mathrm{~s}$ 


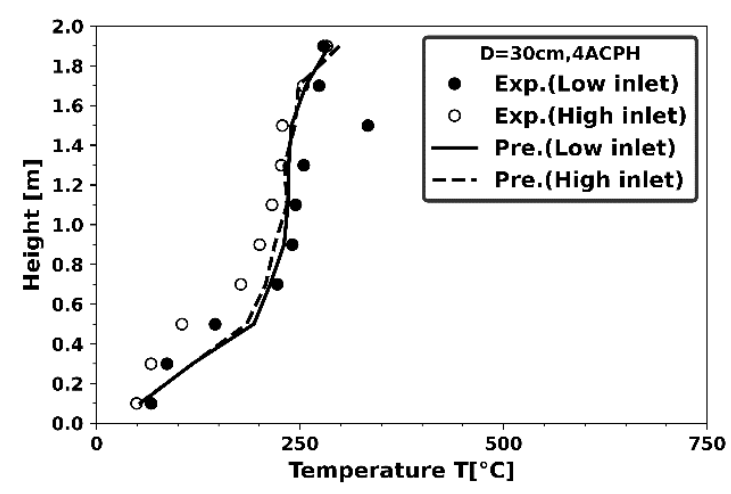

c) $4 \mathrm{ACPH}$ at $\mathrm{t}=250 \mathrm{~s}$

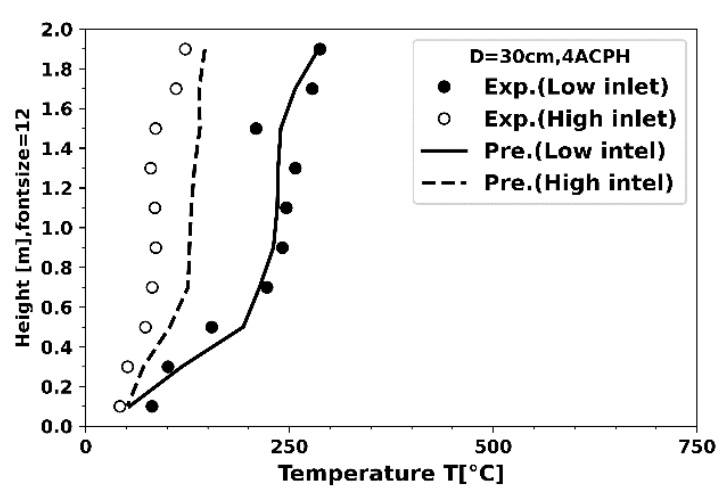

d) $4 \mathrm{ACPH}$ at $\mathrm{t}=500 \mathrm{~s}$

Figure 22. Influence of air intake position on the time history of gas-phase temperature along the right line (TR1-8) for pan diameter of $30 \mathrm{~cm}$.

Fig.23(a, b) shows the time histories of the gas temperature at entrance of the extraction duct for 1 and $4 \mathrm{ACPH}$. During the fire growth period, the gas temperature reaches a peak value of $250^{\circ} \mathrm{C}$ for a low inlet, and $220^{\circ} \mathrm{C}$ for a high inlet regardless of $\mathrm{ACPH}$. During a quasi-steady period, a low ACPH of 1 in high position causes a higher gas temperature of about $200^{\circ} \mathrm{C}$ inside the extraction duct in comparison with the one of about $160^{\circ} \mathrm{C}$ for a low inlet thanks to an improvement of combustion efficiency (cf. Tab.2). With air intake in low position at 4 ACPH, the gas temperature reaches a plateau with a relatively high value of about $230^{\circ} \mathrm{C}$ for many minutes. However, a high inlet at $4 \mathrm{ACPH}$ conducts to a sharp decrease of the smoke temperature starting from around $200 \mathrm{~s}$ due to cooling effect by a strong fresh air jet near the ceiling. For a high inlet (cf. Fig.23b, d), agreement between the prediction and experiment is fair within an error of $25 \%$. With air intake in low position (cf. Fig.23a, c), the prediction follows only approximately the experimental trend with an over-prediction by a factor of $50 \%$.

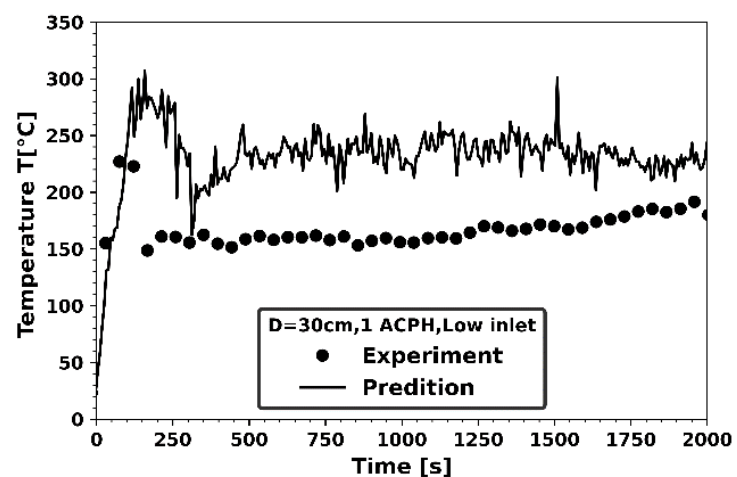

a) Low inlet position at $1 \mathrm{ACPH}$

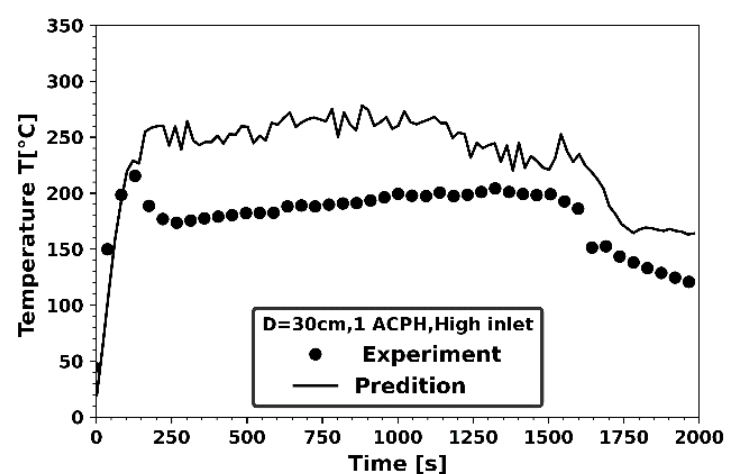

b) High inlet position at $1 \mathrm{ACPH}$ 


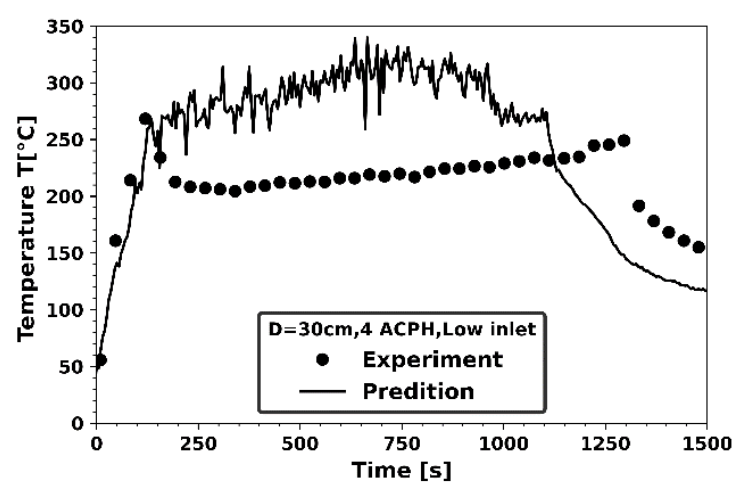

c ) Low inlet position at $4 \mathrm{ACPH}$

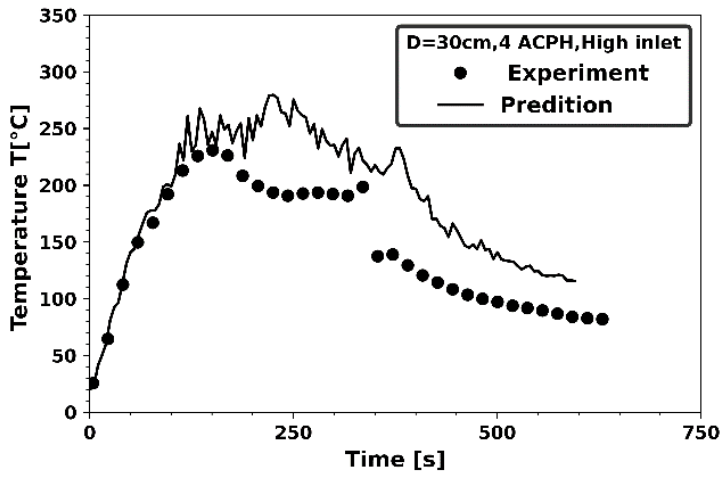

d ) High inlet position at $4 \mathrm{ACPH}$

Figure 23. Time history of gas-phase temperature at entrance of the extraction duct for pan diameter of $30 \mathrm{~cm}$ at 1 and $4 \mathrm{ACPH}$.

The wall temperature has also been identified as a potential risk for the dynamic confinement in order to prevent from hazardous gas leaks. Although concrete of the enclosure is not combustible, the material will be weakened when it is heated up to $700^{\circ} \mathrm{C}$, cracking may easily occur. The time histories of the surface temperature on the behind wall of the enclosure (cf. Fig.1a, b) at a height of $0.48 \mathrm{~m}$ is illustrated in Fig.24(a-d). At a low ACPH of 1, the wall temperature reaches a plateau with a value of about $100^{\circ} \mathrm{C}$ (cf. Fig. $24 \mathrm{a}, \mathrm{b}$ ) regardless of air intake position. At a high ACPH of 4, a low inlet allows to maintain a wall temperature of about $150^{\circ} \mathrm{C}$ (cf. Fig. 24c) during a long time (about $1250 \mathrm{~s}$ ), and however, a high inlet conducts to a decrease of the wall temperature (cf. Fig.24d) starting from about $300 \mathrm{~s}$ due to fire exhaust (cf. Fig.14d). Contribution of the wall temperature to emitting a radiation heat flux over the liquid surface seems less important in comparison with the one from the hot smoke. Agreement between the predicted and measured wall temperature is fair within an error of $30 \%$.

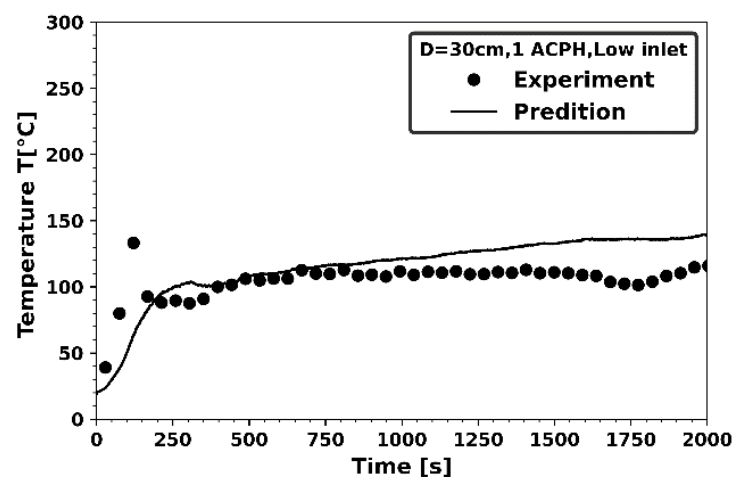

a) Low inlet position at $1 \mathrm{ACPH}$

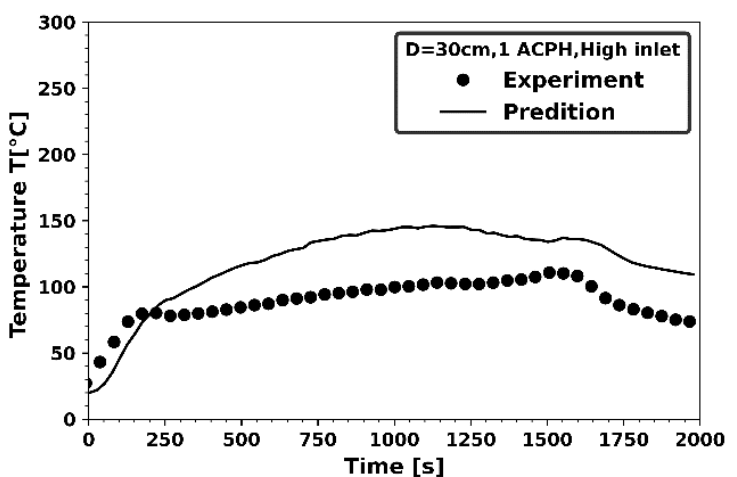

b) High inlet position at $1 \mathrm{ACPH}$ 


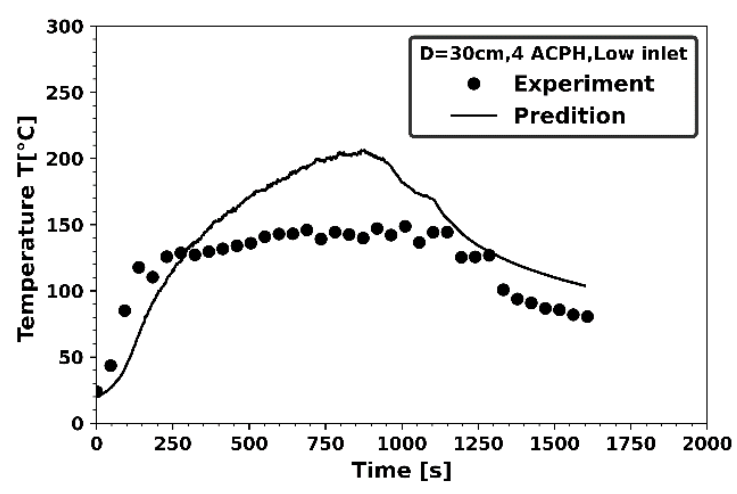

c ) Low inlet position at $4 \mathrm{ACPH}$

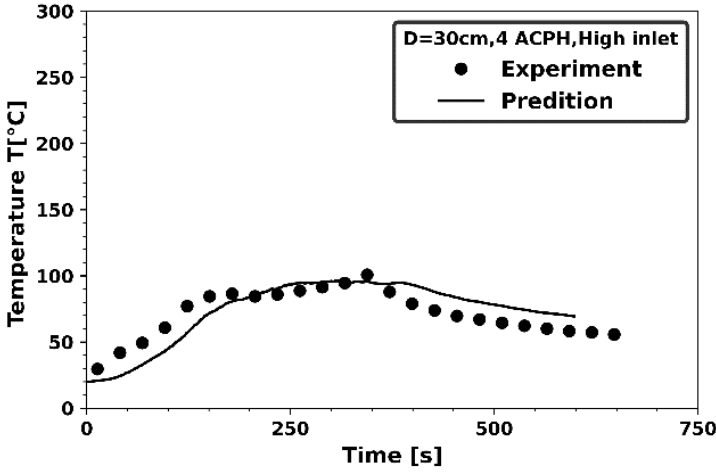

d ) High inlet position at $4 \mathrm{ACPH}$.

Figure 24. Time history of the wall surface temperature for pan diameter of $30 \mathrm{~cm}$ at 1 and 4 ACPH at a height of $0.48 \mathrm{~m}$

Time history of the predicted radiation heat flux over the pyrolysis surface, calculated from Eq.(3), in addition to the measured one is shown in Fig.25(a-d) at 1 and 4 ACPH. For a low inlet at $1 \mathrm{ACPH}$ (cf. Fig.25a), the first period with a high heat flux of about $5 \mathrm{~kW} / \mathrm{m}^{2}$ lasts till $600 \mathrm{~s}$. During the second period when combustion environment is established, the heat feedback from the flame, smoke and wall to the liquid surface tends to provide a constant heat flux of about $2 \mathrm{~kW} / \mathrm{m}^{2}$. A high ACPH of 4 for a low inlet results in an enhancement of heat feedback to the liquid surface due to a strong HRR of about $100 \mathrm{~kW}$ (cf. Fig.13d). During the fire growth period before about $500 \mathrm{~s}$, the heat flux reaches a maximum of $10 \mathrm{~kW} / \mathrm{m}^{2}$. Even when the underventilated condition takes place, a heat flux of $5 \mathrm{~kW} / \mathrm{m}^{2}$ is maintained during a long time up to fire exhaust. Placing the air admission in high position contributes to a sharply decreasing trend of heat flux from about 10 to $2 \mathrm{~kW} / \mathrm{m}^{2}$ mainly due to onset of fire exhaust. The reduced heat feedback for a high inlet leads to a decrease of fuel evaporation rate starting from $250 \mathrm{~s}$, enabling an over-ventilated fire (cf. Fig.14). After the fire growth phase, the heat flux at 4 ACPH increases by a factor of 7 times for a low inlet in comparison with that for a high inlet. The predicted heat flux over the pyrolysis surface shows strong oscillations that were not detected in the experiments. The deviation of the numerical results in relation to the measured heat flux is more than 4 times due to a worse prediction of temperature field above the flame base for under-ventilated fire (cf. Fig.21). The prediction is somewhat improved for the heat flux profiles as long as the fire becomes slightly under-ventilated in the case of fuel pan of 26 $\mathrm{cm}$ (cf. Fig.26) or over-ventilated for fuel pan of $23 \mathrm{~cm}$ (cf. Fig. 27). Although a similar trend between the measured and predicted heat flux is found, an over-prediction by a factor of 2 times is reproduced. During the initial phase, the measured exaggerated spikes of the heat flux are mainly due to a strong perturbation of the attenuation coefficient (Eq.2) via liquid layer depth.
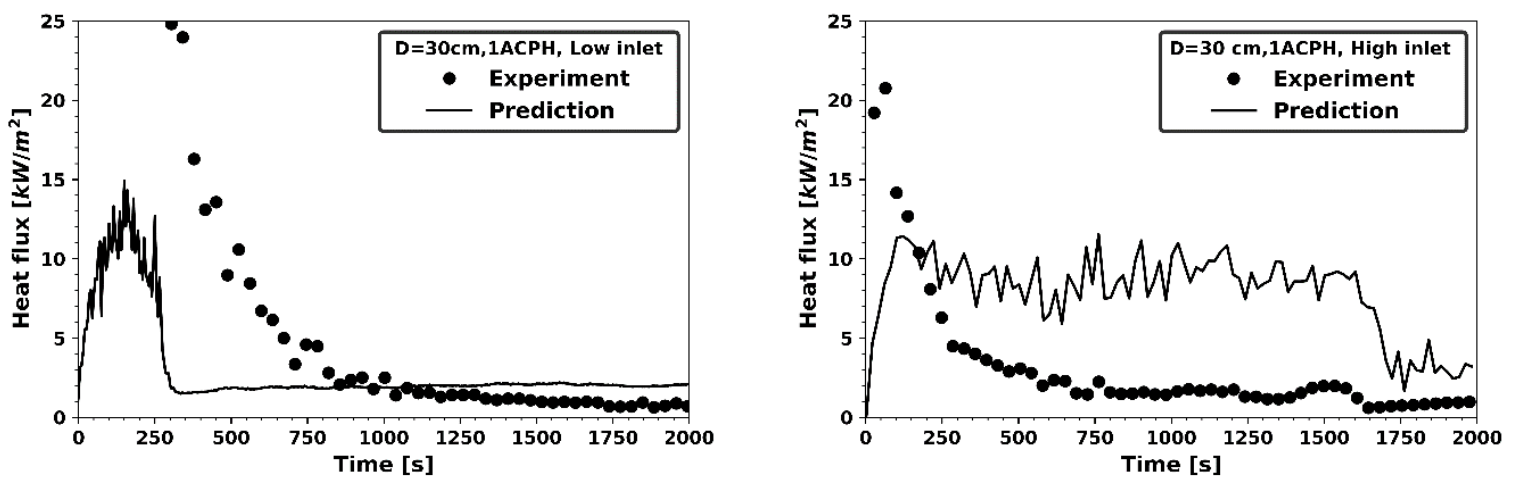
a) Low inlet position at $1 \mathrm{ACPH}$

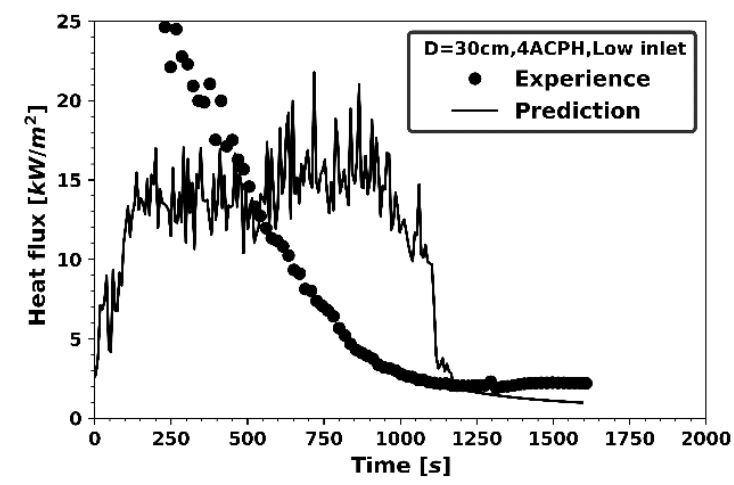

c) Low inlet position at $4 \mathrm{ACPH}$; b) High inlet position at $1 \mathrm{ACPH}$

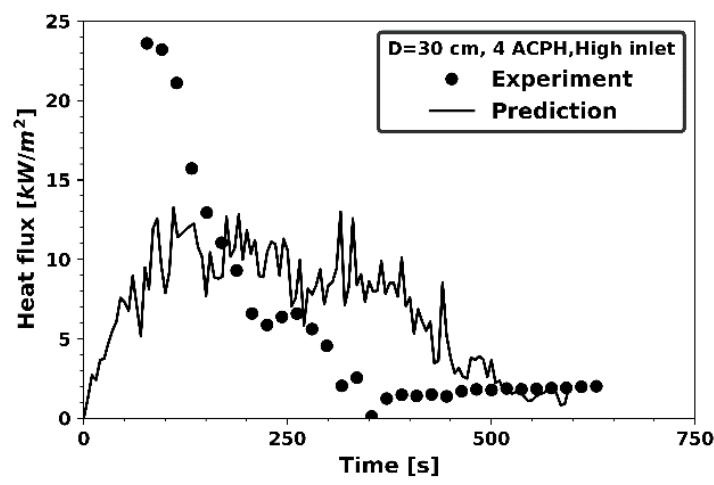

d) High inlet position at $4 \mathrm{ACPH}$.

Figure 25. Influence of air intake position on heat flux over surface of the liquid fuel for pan diameter of $30 \mathrm{~cm}$.

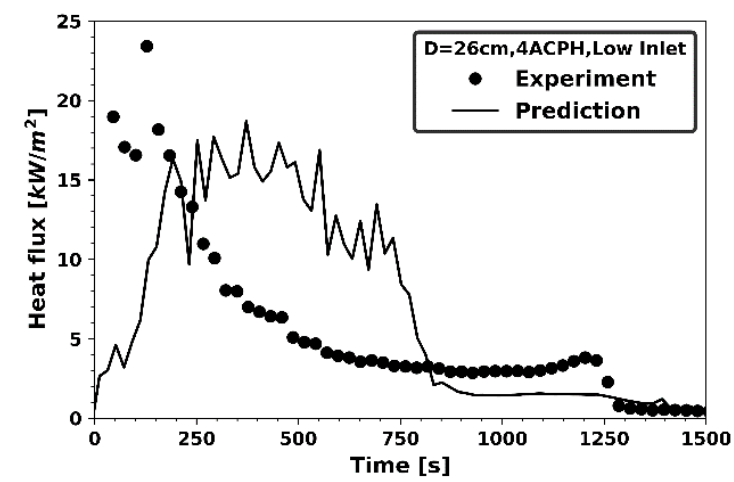

a) Low inlet position

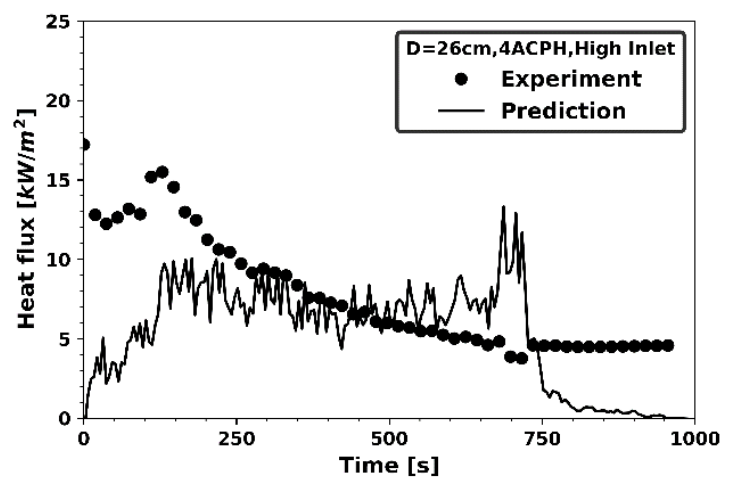

b) High inlet position

Figure 26. Influence of air intake position on heat flux over surface of the liquid fuel for pan diameter of $26 \mathrm{~cm}$ at $4 \mathrm{ACPH}$.

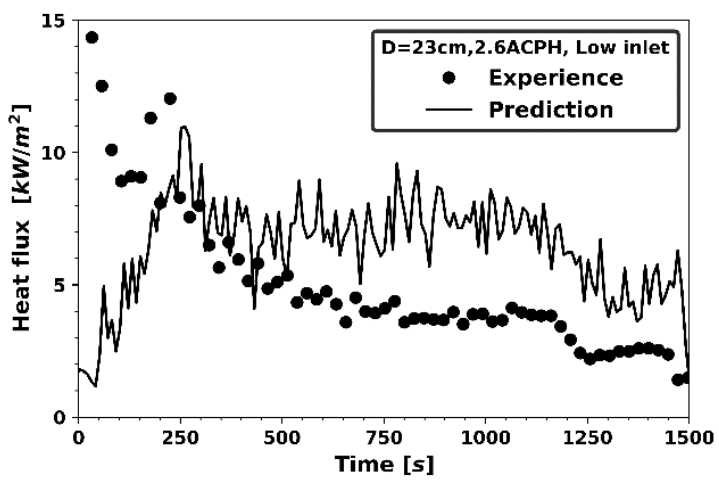

a) Low inlet position

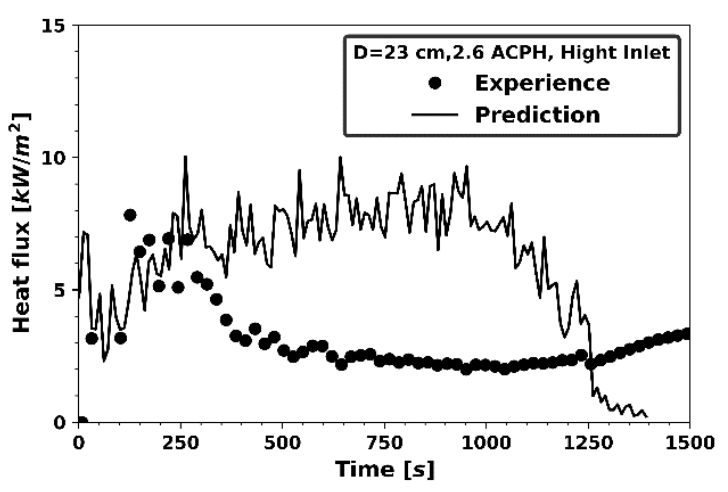

b) High inlet position

Figure 27. Influence of air intake position on heat flux over surface of the liquid fuel for pan diameter of $23 \mathrm{~cm}$

Evolution of the heat flux at the left and right sides with a separation distance of $15 \mathrm{~cm}$ in relation to the central axis of the behind wall (cf. Fig.1a, b) at a height of $0.48 \mathrm{~m}$ is illustrated in Fig.28(a-d). A hot smoke extraction at the right side of enclosure (cf. Fig.20a, b) allows to maintain a wall heat flux of about $1 \mathrm{~kW} / \mathrm{m}^{2}$ at the right side, higher than the one at the left side of about $0.5 \mathrm{~kW} / \mathrm{m}^{2}$. The peak value of the wall heat flux seems insensitive to the inlet position 
at $1 \mathrm{ACPH}$, but a high inlet at $4 \mathrm{ACPH}$ conducts to a rapid decrease of heat flux (cf. Fig.28d) due to fire exhaust (cf. Fig.14d) and cooling effects on the smoke layer near the ceiling. A difference in heat flux between the left and right sides occurs in the experimental results, while the simulations show no difference due to a worse reproduction of the thermal field inside the compartment (cf. Fig.21). The deviation of the numerical results in relation to the measured wall heat flux is more than 3 times (cf. Fig.28c) mainly due to over-prediction of the smoke temperature level (cf. Fig.23).

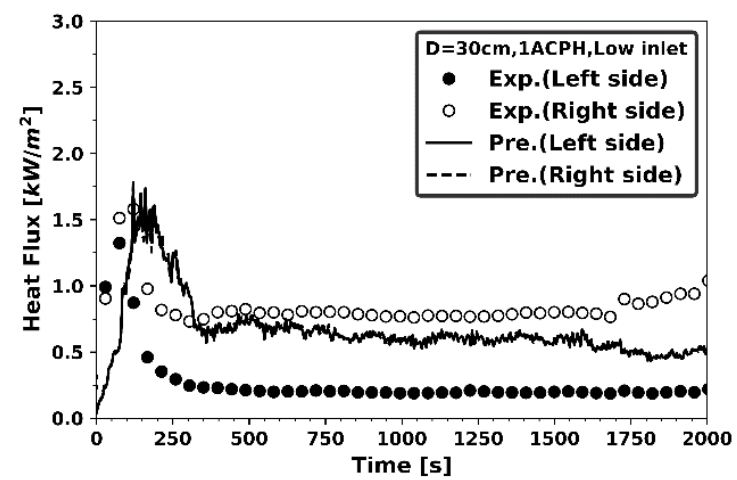

a) Low inlet position at $1 \mathrm{ACPH}$

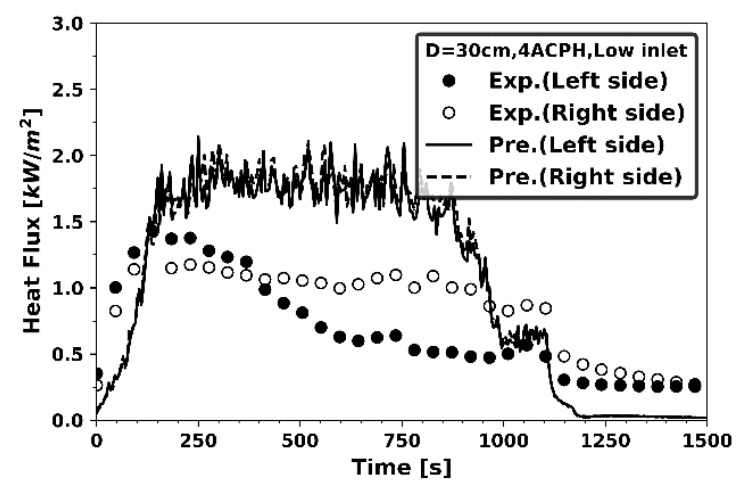

c) Low inlet position at $4 \mathrm{ACPH}$

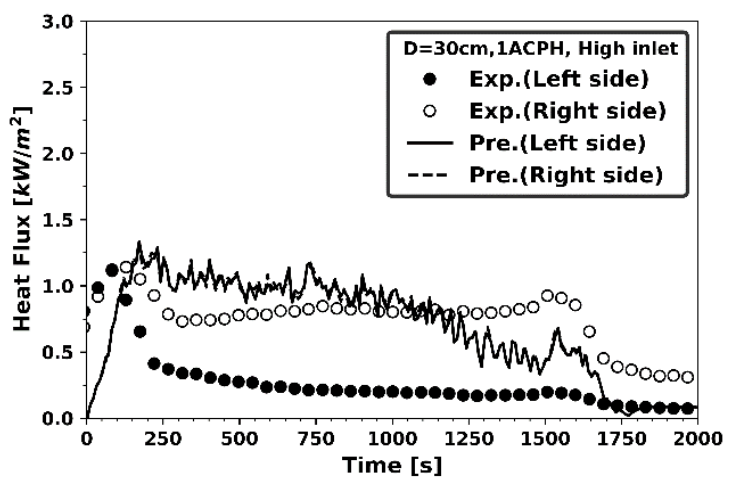

b) High inlet position at $1 \mathrm{ACPH}$

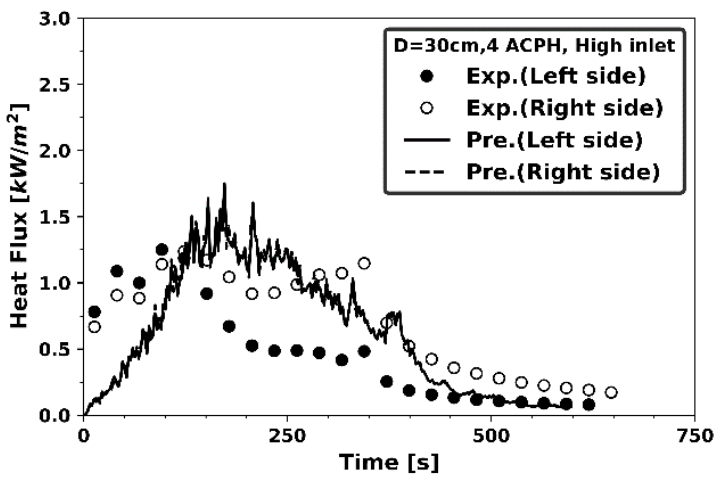

d ) High inlet position at $4 \mathrm{ACPH}$

Figure 28. Influence of air intake position on heat flux over the wall surface at a height of 0.48 $\mathrm{m}$ for pan diameter of $30 \mathrm{~cm}$ at 1 and $4 \mathrm{ACPH}$.

The radiation heat exchanges in a reacting flow depend mainly on three factors: gas temperature, concentrations of gaseous/ particulate soot emitting species, and view factor from flame to the exposed pool. Regardless of air intake position, for a given fire size, the radiation exchanges between the pool fire and the compartment (cf. Fig.28) are smaller compared to the heat feedback from the flame to the pool (cf. Fig.25). This is attributed to the fact that over the exposed pool, gas temperature, concentration of emitting species and view factor are found to be higher for the radiation exchanges. Air intake in low position at $4 \mathrm{ACPH}$ is found to increase the fire growth size with a more important effective HRR (cf. Fig.13d) compared to the one with a high inlet (cf. Fig.14d). Therefore, there is a greater heat feedback from the flame in the low inlet case (cf. Fig.25c) than the one in the high inlet case (cf. Fig.25d), mainly due to an increase in view factor via fire size attached to an effective HRR. To the knowledge of the authors, any attempt to draw a general conclusion for all ACPH is discouraged. This is mainly attributed to the two competing interaction mechanisms for the radiation exchanges: soot formation and gas temperature both depending on the fire dynamics regime such as under or over ventilated fire. Less soot formation results in an increase of gas temperature, and inversely, more soot conducts to a decrease of gas temperature via radiation loss. 


\section{CONCLUSIONS}

These findings indicate that the admission duct in low position is the most severe situation for the fire growth rate, particularly with an increase of ACPH due to improvement of air entrainment towards the fire base. Moreover, the smoke temperature near the ceiling, which reaches about $350^{\circ} \mathrm{C}$ with low air admission, contributes to an enhanced heat feedback to the pyrolysis surface of liquid fuel. Burning of fuel pan of $30 \mathrm{~cm}$ becomes quickly ventilation controlled with air admission in low position due to an increase in mass loss rate. Air intake position influences significantly the fire dynamics only in under-ventilated conditions. Changing air intake position from low to high contributes to a decrease of the peak value of HRR by a factor of about $55 \%$. In particular, a high inlet reduces the possibility of a quick fire growth with an increase of ACPH due to a decrease in heat feedback to liquid surface and a difficulty in air entrainment towards the fire base. When the admission duct is placed in high position, a flame exhaust happens early with a reduction in fire duration by a factor of 2.5 times by increasing $\mathrm{ACPH}$ from 1 to 4 in comparison with the case of a low inlet.

The work is continuing with the aim of developing a combustion model respective to the chemical kinetic depending on the gas temperature in a vitiated air environment. Coupling effects between pressure variations and oxygen feedings through the inlet should be improved by reproducing correctly the complex turbulent flow instabilities inside enclosure. Effect of the turbulence models implemented in FDS on the predicted quantities is less important by using a grid size in an order of centimeter due to numerical diffusion. The absorption coefficient employed in the radiation model via soot formation should be significantly improved by incorporating the physical processes of inception, coagulation and surface growth for prediction of heat flux. The future investigation aims also to measure a more detailed chemical species for evaluation of the combustion efficiency of an enclosure fire in under-ventilated conditions via measured effective HRR.

\section{REFERENCES}

[1] Pretrel, H., and Audouin, L. 2010. Smoke movement induced by buoyancy and total pressure between two confined and mechanically ventilated compartments. In Interflam 2010, Proceedings of the Twelfth International Conference, Vol. 2, Interscience Communications, London, p.1053- 1064.

[2] Pretrel, H., Querre, P., and Forestier, M. 2005. Experimental study of burning rate behavior in confined and ventilated fire compartments. In Fire Safety Science-Proceedings of the Eighth International Symposium, Vol. 8, International Association for Fire Safety Science, pp. 1217-1229.

[3] Mélis, S. and Audouin, L., Effects of vitiation on the heat release rate in mechanicallyventilated compartment fires, Fire Safety Science - Proceeding of the Ninth International Symposium, International Association for Fire Safety Science, 2008.

[4] Peatross, M. J. and Beyler, C. L., Ventilation effects on compartment fire characterization", Fire Safety Science - Proceeding of the Fifth International Symposium, International Association for Fire Safety Science, 1997, pp 403-414.

[5] Alvares, N., Foote, K. and Pagni, P., (1984) Forced ventilation enclosure fires, Combustion Science and Technology, 39: 55-81. 
[6] B. Magnognou, J. P. Garo, B. Coudour and H. Y. Wang, Risk assessment of unburnt gas Ignition in an exhaust system connected to a confined and mechanically ventilated enclosure fire, Journal of Fire Safety, 91:291-302, 2017.

[7] Simo Hostikka, Rahul Kallada, Umar Riaz, Topi Sikanen, Fire-induced pressure and smoke spreading in mechanically ventilated buildings with air-tight envelopes, Fire Safety Journal 91 (2017) 380-388.

[8] C. Forneau, C. Delvosalle, H. Breulet, S. Desmet, S. Brohez, Comparison of fire hazards in passive and conventional houses, Chem. Eng. Trans. 26 (2012) 375-380.

[9] P. Blomqvist, L. Rosell, M. Simonson, Emissions from fires part II: Simulated room fires, Fire Technol. 40(2004) 59-73.

[10] A. S. X. Loo, A. Coppalle, J. Yon, P. Aîné, Time-dependent smoke yield and mass loss of pool fires in a reduced-scale mechanically ventilated compartment, Journal of Fire Safety, 81:32-43, 2016.

[11] S. Ukleja, M.A. Delichatsios, M.M. Delichatsios, J. Zhang, Smoke concentration inside and outside of a corridor-like enclosure, Journal of Fire Safety, 60:37-45, 2013.

[12] J. Lassus, E. Studer, J.P. Garo, J.p. Vantelon, P. Jourda, P. Aine. Influence of ventilation on ignition risk of unburnt gases in the extraction duct of under ventilated compartment fire. Combust.Sci and Tech, 182, pp.517-528, 2010.

[13] Zavaleta, P. and Audouin, L. (2018) Cable tray fire tests in a confined and mechanically ventilated facility, Fire and Materials, 42:28-43.

[14] Takeda (1985) Oscillatory phenomenon and inverse temperature profile appearing in compartment fires, Combustion and Flame, 61:103-105.

[15] Hu, Z., Utiskul, Y., Quintiere, J.G., Trouvé, A. (2005) A comparison between observed and simulated flame structures in poorly ventilated compartment fires, Fire Safety Science Proceedings of the Eighth International Symposium, 1193-1204.

[16] V. Babrauskas, Estimating large pool fire burning rates, Fire Technol. 19, 1983, 251-261.

[17] B.D. Ditch, J.L de Ris, T.K. Blanchat, M. Chaos, R. G. Bill, S.B. Dorofeev, Pool fires-

An empirical correlation, Combust. Flame 160(12), 2013, 2964-2974.

[18] S. Vilfayeau, N. Ren, Y. Wang, A. Trouvé. Numerical simulation of under-ventilated liquid-fueled compartment fires with flame extinction and thermally-driven fuel evaporation. Proceedings of the Combustion Institute 35 (2015) 2563-2571.

[19] T. Sikanen and S. Hostikka, Predicting the heat release rates of liquid pool fires in mechanically ventilated compartments, Fire Safety J. 91(2017) 266-275.

[20] J. Wahlqvist, P. van Hees, Validation of FDS for large-scale well-confined mechanically ventilated fire scenarios with emphasis on predicting ventilation system behavior, Fire Saf. J. 62B (2013) 102-114.

[21] W. Wegrzynski and G. Vigne, Experimental and numerical evaluation of the influence of the soot yield on the visibility in smoke in CFD analysis, Fire Safety Journal, 91(2017) 389398.

[22] R. K. Janardhan, S. Hostikka, Experiments and numerical simulations of pressure effects in apartment fires, Fire Technol. 53(2017) 1353-1377.

[23] D. Stroup and A. Lindeman. Verification and Validation of Selected Fire Models for Nuclear Power Plant Applications. NUREG-1824, supplement 1, United States Nuclear Regulatory Commission, Washington, DC, 2013. 37.

[24] K. Mcgrattan, R. Mcdermott, S. Hostikka and J. Floyd (2013) Fire Dynamics Simulator (Version 6), User's guide, NIST Special Publication.

[25] E.E. Zukoski, Fluid dynamics aspects of room fires, First International Symposium on Fire Safety Science, (1984) 1-30.

[26] A. Nasr, S. Suard, H. El-Rabii, J.P. Garo, L. Gay, L. Rigollet, Heat feedback to the fuel 
surface of a pool fire in an enclosure, Fire Safety Journal, 60(2013) 56-63.

[27] J. Richard, J.P. Garo, J.M. Souil, J.P. Vantelon, D. Lemonnier, Addition of a water mist on a small-scale liquid pool fire: effect on radiant heat transfer at the surface, Proc. Combust. Inst. 29 (2002) 377-384.

[28] A. Murty Kanury, Introduction to Combustion Phenomena, New York: Gordon, ISBN 0677-02690-0, 1984.

[29] Moss, J.B., Stewart, C.D., Young, K.J. (1995) Modelling soot formation and burnout in a high temperature laminar diffusion flame burning under oxygen-enriched conditions, Combustion and Flame, 101, pp. 491-500.

[30] A. Tewarson (2002) Generation of Heat and Chemical Compounds in Fires. SFPE Third edition, p.3-82.

[31] The SPFE Handbook of Fire Protection Engineering, National Fire Protection Association, Greenbelt, MD, Chapter 16:486-528, 2016.

[32] J. Floyd, Coupling a Network HVAC model to a computational fluid dynamics model using large eddy simulation, Fire Safety Science, in Proceedings of the Tenth International Symposium, 2011, pp.459-470.

[33] N.P. Bryner, E.L. Johnsson, W.M. Pitts, Carbon monoxide production in compartment fires: reduced-scale enclosure test facility, National Institute of Standards and Technology, NISTIR-5568, 1994.

[34] NFPA (National Fire Protection Association), Standard growth curves, BRE-Project, 2009. 